\title{
Silk-based stabilization of biomacromolecules
}

Adrian B. $\mathrm{Li}^{1}$, Jonathan A. Kluge ${ }^{2}$, Nicholas A. Guziewicz ${ }^{3}$ Fiorenzo G. Omenetto ${ }^{1}$, David L. Kaplan ${ }^{1,2, *}$

${ }^{1}$ Department of Chemical and Biological Engineering, Tufts University, 4 Colby Street, Medford, MA 02155, USA

${ }^{2}$ Department of Biomedical Engineering, Tufts University, 4 Colby Street, Medford, MA 02155 , USA

${ }^{3}$ Drug Product Technologies, Amgen, 1 Amgen Center Drive, Thousand Oaks, CA 91320, USA

*Corresponding author. Phone: 617-627-3251; Fax: 617-627-3231; E-

mail: david.kaplan@,tufts.edu

Keywords: silk, stabilization, recovery, biologics, mechanisms, processing, interactions

\section{Abstract:}

Silk fibroin is a high molecular weight amphiphilic protein that self-assembles into robust biomaterials with remarkable properties including stabilization of biologicals and tunable release kinetics correlated to processing conditions. Cells, antibiotics, monoclonal antibodies and peptides, among other biologics, have been encapsulated in silk using various processing approaches and material formats. The mechanistic basis for the entrapment and stabilization features, along with insights into the modulation of release of the entrained compounds from silks will be reviewed with a focus on stabilization of bioactive molecules. 


\section{Introduction:}

Proteins are gaining traction as therapeutics, biomarkers for diagnostics, and various other industrial applications. This traction has prompted recent interest in methods of protein stabilization. Maintenance of their integrity during processing and storage is crucial to their utility. The inherent labile nature of proteins due to the complex chemistry and structure, however, presents a challenge in the development of protein formulations. Currently, a majority of these formulations require some form of cold chain (e.g., refrigeration of freezing) storage, which can be costly and prohibitively difficult in areas with limited resources.

Silk fibroin, a biologically derived protein harvested from domesticated silkworm (Bombyx mori) cocoons, is an attractive material system to use in the immobilization and preservation of biological samples. Silk is a mechanically robust structural material, allowing for the formation of materials and devices that can withstand rough handling caused during transport [1]. The ambient and all-aqueous processing utilized during fibroin purification facilitates device fabrication without loss of bioactivity to the entrapped materials. Conversely, many synthetic polymers require harsh processing conditions or result in acidic byproducts that could degrade encapsulated proteins [2]. Moreover, silk, due to its hydrophobic nature and crystallization, is inherently more resilient against changes in temperature, moisture and $\mathrm{pH}$ than other natural, synthetic, and biopolymers [3].

Purified silk protein can also be processed into various material formats which are conducive to uses as self-standing storage and stabilization matrices. For example, air dried silk films could be generated in remote field locations where more technologically advanced resources are limited. Conversely, with appropriate fabrication, silk films with integrated sensing or electronic interfaces can also be constructed [4]. Silk materials are optically transparent [5] to permit tracking entrained bioactive compounds in some instances, and the option for lyophilized silk formulations for shelf-stable feedstocks offers tremendous versatility for silk as a medium for a broad range of stabilization needs.

The versatility of silk protein stems in part from the variety of secondary structures that can arise from the extended amino acid sequence [6]. The primary sequence is similar to a block copolymer structure, composed of approximately $94 \%$ hydrophobic domains containing smaller and less reactive side chains and a balance of hydrophilic linker regions, enabling the coexistence of random coils, $\alpha$-helices, and $\beta$-sheets [7]. The protein is polymorphic, mostly found in two structures. The first, Silk I, consists mainly of random coils, and is amorphous, nonphysically crosslinked, and non-crystallized. The second, Silk II, consists mainly of crystalline $\beta$ sheet structures crosslinked through hydrogen bonding, which generally renders silk materials insoluble. In nature, the Silk I structure is found in the silk producing glands of the silkworm, while Silk II is found as spun fibers. This highly unusual structure found in silk allows bioactive compounds to be immobilized in and reconstituted from a highly thermostable dehydrated state that protects against degradation stresses during both processing and storage. Additionally, silk is nonimmunogenic and also degrades into amino acids, resulting in low inflammation [8].

Herein, we review the major considerations involved when assessing stabilizers in order to understand the rational design of silk formulations for stabilization of bioactive molecules. First, we highlight the current state-of-the-art in silk-based stabilization of biomolecules. In order to 
understand silk's protective mechanisms, we then identify common protein degradation stresses and practical means of their remediation or mitigation. Because proteins have been the primary targets requiring stabilization via silk, this review focuses mainly on protein molecules. Silkspecific stabilization mechanism hypotheses are then distilled from the vast number of potential modes of degradation. Thus far, a majority of mechanistic studies with biological analytes have been in the context of sustained release. Therefore, studies that have modulated silk fabrication processing conditions in the context of optimizing biological entrapment will also be reviewed as well as other non-silkworm silks used in a stabilization context. Due to the similarities between stabilization and sustained release, we expect that the insights gained will translate practically to stabilization studies and applications.

\section{Section 1: Silk as a stabilizer}

The entrapment and release of bioactive molecules from silk has been widely studied and summarized [9-11]. Prior reviews consolidate substantial indirect evidence supporting the theory that silk-molecule interactions in solid or liquid states promote the retention of native molecular structure and bioactivity of these molecules. One recent review organized the many compounds stabilized in silk and focused on insoluble silk matrices utilized for controlled release [12]. Here, we focus mainly on forms of silk that are fully soluble systems, which are more conducive to situations in which complete recovery of the entrapped analyte is preferable. With this focus in mind we review the various compounds entrapped in silk with the intent for immediate recovery, including enzymes, antibiotics, vaccines, and blood-derived proteins.

\section{Silk Structures}

Processing native silkworm cocoons into usable materials first requires separation of the core fibroin protein from the cladding sericin protein. This process typically involves immersion in boiling sodium carbonate solution in a process called de-gumming, followed by disruption of the crystalline $\beta$-sheet structure to generate a solution of the protein [13]. The native protein that makes up the core of the fibers is silk fibroin, which is formed as a dimer, composed of a heavy $\sim 390 \mathrm{kDa}$ chain and a light $\sim 25 \mathrm{kDa}$ chain [14]. Depending on the extraction time during degumming, the silk fibroin protein molecular weight and polydispersity can be tuned [15]. Further, control over the polymorphic structure of silk in solution and in the solid state impact stability and solubility/solubilization. These structures are influenced by physicochemical parameters including shear, $\mathrm{pH}$, concentration, salts, and time during processing. These timedependent changes on silk polymorphism have a direct consequence on material properties generated from solutions of silk proteins prepared as above. In these subsections, we outline the practical applications in which these silk structures can be employed and further processing strategies germane to these formats will be reviewed in Section 3. From here on, we will refer to silkworm silk fibroin as silk, for the sake of simplicity, throughout the rest of the review unless otherwise noted.

\section{Solution}

In order to exploit new material uses and technological applications for reconstituted silk fibroin, a major limitation is the challenge in stabilizing fibroin in solution. When stored at $4{ }^{\circ} \mathrm{C}$, aqueous fibroin remains in the liquid state up to 3-4 months (depending on concentration), prior to the onset of a sol-gel transition characterized by rapid increases in $\beta$-sheet structure [16]. This transition is accelerated at ambient temperatures as well as at higher concentrations or lower $\mathrm{pH}$ 
[17]. Additionally, the age (time since extraction/purification) of the silk solution [18] and concentration at which it is stored [19] have a significant impact on the structure and stability of the material, which has downstream effects on the generation of materials [20]. Therefore, new approaches are needed to circumvent silk fibroin liquid storage requirements in order to provide a more stable feedstock for liquid stability applications. Initial studies suggest that lowering the molecular weight and concentration, and targeting systems with high $\mathrm{pH}$ buffering conditions are suitable approaches to enable the utilization of silk solutions over extended time frames, and in turn exploiting stabilization features of silk [21].

\section{Air-Dried Films}

The use of air drying to remove the aqueous phase of silk materials is the simplest and most heavily studied format of silk used to stabilize compounds. The ubiquity holds even though it is a technique requiring tight control of solution and drying parameters in order to generate structures and functions of interest and with reproducible outcomes. As indicated above, the use of a high concentration of silk during water removal facilitates self-assembly via compaction of $\beta$-sheet rich crystalline domains; therefore, soluble films are generally formed using lower concentrations of silk that are dried quickly. Bulk-loaded silk films, which are fabricated through dehydration of the combined silk solution and biological components in one mixture, can be prepared such that the water solubility of the silk film is retained [22]. This strategy allows rapid recovery of compounds loaded into silk materials in applications where sustained release or long-term immobilization is not desired.

Another major advantage of the film and air drying approach is the ability to deploy this format onto a variety of surfaces of arbitrary geometry. Recently, it has been shown that deploying low molecular weight silks through inkjet printing was a viable method to deposit small and highly accurate solutions containing silk and stable dopants [23]. Functional silk inks were prepared by adding nanoparticles, enzymes, antibiotics, growth factors, and antibodies to the inks prior to printing [23]. For example, a colorimetric bacterial sensor was fabricated by directly printing functionalized silk inks onto various substrates (e.g., paper, transparent plastic sheets, surgical gloves). Using these substrates and other conformal formats $[22,24]$ for silk films and coatings can enable new integrated stabilization features for biological sensors.

\section{Lyophilization}

Lyophilization (e.g., freeze-drying) is a historical technique that is now advanced via engineering controls to allow for removal of upwards of $99 \%$ water from stabilization matrices. Unlike options of air/vacuum drying or spray drying silk solutions, sublimation via lyophilization can maximize solubility of the silk material by minimizing exposure to the air-liquid interface during elimination of residual water. Air- or vacuum-assisted drying of silk can result in the formation of partially insoluble mixtures of Silk I and Silk II structures [25], with time at high concentration being a critical factor [19]. Sublimation, on the other hand, is a more appropriate water removal method for silk-based material storage formats because it results in soluble Silk I structures [26], due to a lack of freezing-induced crystallization.

Key to lyophilization are the initial freezing conditions including time and temperature in order to establish a well-connected and adequately-sized ice crystal network amongst the polymer/encapsulate/buffer solute structure. In the drying phases that follow, this ice network will be a physical path for water removal, and thus care must be taken to avoid the collapse of 
the structure by maintaining the polymer and bulk solute in a stable, structured state. Practically, this is performed by maintaining the bulk temperature $1-2^{\circ} \mathrm{C}$ below the solution glass transition temperature, $\mathrm{T}_{\mathrm{g}}$, [27], which for silk protein is roughly $-11^{\circ} \mathrm{C}$ [28]. A protein system like silk with a relatively high $\mathrm{T}_{\mathrm{g}}$ ' compared to sugar systems is attractive because it can allow for shorter lyophilization process times and a broader range of freezing conditions which can enhance stability [29]. Various buffers and excipients can alter this setpoint for a given silk formulation, thus careful evaluation of $\mathrm{T}_{\mathrm{g}}$ ' and the quality of the final dried silk matrix is required in order to maintain a quality product.

\section{Compounds Stabilized In Soluble Silk Structures}

\section{Enzymes}

Stabilization of enzymes in silk biomaterials, particularly bulk-loaded films, has been reported for various enzymes including horseradish peroxidase (HRP), glucose oxidase, lipase, organophosphorus hydrolase, among others. Studies to date have focused primarily on the homogeneous introduction of enzymes into a silk solution prior to air drying into a film format. HRP is widely used in diagnostics and testing applications as an indicator enzyme, including in immunoassays and sensors. The enzyme, however, has poor stability in the liquid state. The addition of silk to an HRP solution increased enzyme activity $30-40 \%$ and increased the half-life of HRP stored at room temperature to 25 days (compared with $2.5 \mathrm{~h}$ for HRP in buffer alone). After 5 months of storage, HRP immobilized in air dried silk films retained $24 \%, 22 \%, 17 \%$ of initial activity when stored at $4^{\circ} \mathrm{C}$, room temperature, and $37^{\circ} \mathrm{C}$, respectively [30]. HRP activity was also preserved when incorporated via bulk-loading into silk optical gratings [31] and silk microneedle arrays [32]. The response of hydrogen peroxide sensors based on HRP immobilized in silk films decreased only $16 \%$ after 2 months of storage at $4^{\circ} \mathrm{C}$ [33]. Likewise, HRP-doped silk ink solutions retained $82 \%$ of initial enzymatic activity for up to 6 days, compared with $6 \%$ activity detected for HRP in water alone (e.g., without silk) when stored on the laboratory bench at ambient conditions (no lyophilization) [23].

Glucose oxidase (GOx) is utilized in commercial ampometric sensors for the detection of glucose in solution. GOx immobilized in air dried silk films retained more than $90 \%$ relative activity after soaking in phosphate buffer at $\mathrm{pH} 7$ at $4{ }^{\circ} \mathrm{C}$ for 4 months [34]. Immobilization of GOx in silk fibroin improved activity at elevated temperatures compared with the free enzyme but also improved stability compared with the enzyme immobilized in gelatin films, which were unstable at elevated temperatures [35]. A more recent study showed that soluble films loaded with $1 \mathrm{wt} \% \mathrm{GOx}$ and stored at $4^{\circ} \mathrm{C}$ and $25^{\circ} \mathrm{C}$ over 5 months of storage, exhibited increased GOx activity above $100 \%$ of the initial activity [36]. This increase in activity over time was attributed to renaturation of the GOx protein that was facilitated by entrapment in silk. Interestingly, methanol treatment of the same GOx-entrapped films induced less stability as a result of increased crystallinity, suggesting the role of hydrophobic interactions between the GOx and silk molecules as an important feature in maintaining biological functions of this enzyme. GOx has also improved stability when mixed with $1 \mathrm{w} / \mathrm{v} \%$ silk solutions when compared to more dilute silks and has dramatically improved stability over GOx in PBS solutions, where the enzyme is quite labile.

The ability of silk to stabilize lipase in solution and air dried film formats was also demonstrated where stability was highest in non-crystallized formulations [36]. The performance of silk in 
protecting HRP and GOx was not as strong as the stabilizing seen with lipase, but was nonetheless significant compared to controls. Organophosphorus hydrolase (OPH) is a bacterial enzyme which holds promise as an effective agent for the bioremediation of organophosphates. Entrapment of OPH in silk films resulted in the stabilization of OPH activity under a variety of conditions that would otherwise reduce enzyme activity when free in solution, such as elevated temperature, UV light exposure and detergent. Silk entrapment of OPH also allowed for dispersal into a polyurethane-based coating that retained organophosphate hydrolysis activity after formulation, coating application and drying [37].

\section{Antibiotics}

Due to the challenges in the worldwide distribution of antibiotics to remote areas and developing countries, stabilization of small molecule antibiotics is of interest from a therapeutic perspective. Incorporation of penicillin and tetracycline into silk films dramatically improved stability compared with storage in solution, and also improved stability compared with storage as dry powders [38]. Air dried Tetracycline-loaded films demonstrated no loss of activity over a 4 week time period when stored at $4^{\circ} \mathrm{C}, 25^{\circ} \mathrm{C}$ (with or without light exposure), and $37^{\circ} \mathrm{C}$, and only a $20 \%$ loss of activity when stored at $60^{\circ} \mathrm{C}$, a significant improvement in stability over tetracycline in solution. Stabilization and protection persisted above physiological temperatures (e.g., up to $60^{\circ} \mathrm{C}$ ) and for extended time frames (e.g., up to 6 and 9 months). Tetracycline bioactivity was also preserved during fabrication of silk microneedle arrays with subsequent release studies against Staphylococcus aureus [32]. The stability of ampicillin incorporated into silk inks was higher than ampicillin stored in water after printing at various temperatures from $4^{\circ} \mathrm{C}$ (refrigerator temperature) to $37^{\circ} \mathrm{C}$ (body temperature) [23]. This combination of silk conformal formats and maintenance of antibiotic bioactivity offers the ability to topographically control drug distribution, providing options for rapid antimicrobial assays that could identify the minimum inhibitory concentration and evaluate the susceptibility of certain antibiotics.

\section{Vaccines}

Molecules more complex than enzymes have been stabilized in silk, including live viral vaccines. One such target was the Measles, Mumps, and Rubella (MMR) live viral vaccine, which was evaluated for solution, film, and lyophilized silk interactions [38]. Results of accelerated aging studies showed significant improvements of the lyophilized formats over air dried formats due to decreases in residual moisture content of the lyophilized systems. Both films and lyophilized matrices significantly improved viral activity retention vs. control vaccines that were re-lyophilized samples. In studying the vaccine-silk interactions, there were improvements in the thermal stability of the formulation of vaccines in the presence of silk compared to the vaccine alone. This effect was shown via an increase in glass transition temperature. Likewise, aggregation of viral particles was reduced in silk solution in comparison to water, based on dynamic light scattering.

Bacteriophages are being developed as highly specific antibacterial agents for control of some pathogenic bacteria, and formulated therapeutics containing phages will potentially be subject to stabilization challenges. A system of similar complexity to the MMR vaccine was developed to compare viral stability in various silk sources [39]. Air-dried silk/virus solutions were prepared and modified plaque assays were used to test stability of honeybee silks. The stabilizing ability was compared to hornet and silkworm silks, and bovine serum albumin (BSA), as a control. 
Silkworm silk was able to stabilize the virus (virus loss of $4.2 \% /$ day at $37^{\circ} \mathrm{C}$ ), although the virus infectivity half-life at $37^{\circ} \mathrm{C}$ was less than in the MMR study. The honeybee and hornet silk proteins in the study were also able to stabilize the virus, and all silks improved the preservation of virus infectivity when compared to BSA. BSA also conferred considerable stabilization against exposure to elevated temperatures relative to the absence of added protein.

\section{Plasma Molecules}

Four heme-containing proteins (myoglobin, hemoglobin, horseradish peroxidase, catalase) incorporated into air dried regenerated silk films on graphite electrodes (GE) retained their ability to catalyze the reduction of hydrogen peroxide and nitric oxide [40]. The investigation of UV-Vis and reflectance absorption infrared (RAIR) spectroscopy showed that the heme-proteins entrapped in silk maintained their native states, while scanning electron microscopy (SEM) and RAIR indicated presence of an intermolecular interaction between the heme-proteins and the silk. Hemoglobin has also been successfully encapsulated in silk diffraction gratings in order to detect dissolved oxygen [41].

\section{Compounds Stabilized In Insoluble Silk Structures}

Many other compounds have been encapsulated in silk structures for the purpose of sustained delivery, and have been previously reviewed [10,12]. Briefly, other enzymes stabilized in insoluble silk constructs include cholesterol oxidase (ChOx), tyrosinase, ribonuclease, alkaline phosphatase (ALP), $\beta$-glucosidase, uricase, L-asparaginase (ASNase), and phenylalanine ammonia-lyase (PAL). Stabilized growth factors include bone morphogenetic protein 2 (BMP-2), fibroblast growth factor 2 (FGF-2), insulin-like growth factor 1 (IGF-1), parathyroid hormone (PTH), basic fibroblast growth factor (bFGF), nerve growth factor (NGF), glial cell derived neutrophic factor (GDNF), and vascular endothelial growth factor (VEGF). Stabilized proteins include staphylococcal low molecular weight protein, immunoglobulin $\mathrm{G}$ monoclonal antibody $(\operatorname{IgG})$, green fluorescent protein, NeutrAvidin, and insulin. Stabilized small molecules include adenosine, chlorophyll a $\beta$-carotene Astaxanthin, olive leaf antioxidants oleuropein and rutin, doxycycline ciprofloxacin, curcrumin, doxorubicin, phenol red, 4-amino-benzoic acid, inulin, dextran, and azoalbumin. Various genes have been delivered via plasmid DNA (pDNA) and adenovirus release using bioengineered silk carriers to stabilize the genetic material.

\section{Stabilization with Silk from Alternative Sources}

The stabilizing ability of silk is not exclusive to silk sourced from Bombyx mori silkworms. Spider silk also shares the robust mechanical properties, biocompatibility, and biodegradability as silkworm silk, but can be difficult to harvest due to the cannibalistic nature of spiders [42]. Thus, recombinant spider silk proteins (RSSP) have been developed for biomedical applications [43]. Both bone sialoprotein (BSP) [44], and dentin matrix protein 1 (DMP1) [45] have been formed as chimeras with RSSP to promote bone regeneration. RSSP has also been used to encapsulate small molecule drugs [46], proteins [47], cancer cell targeted gene carriers [48], and enzymes [49]. Recombinant honeybee silk and regenerated hornet silk, which tend to form coiled-coil structures and are less is repetitive and smaller in molecular weight in contrast to silkworm silk, were evaluated as described above and shown to be comparable to silkworm silk [50]. Honeybee silk was also shown to retain myoglobin activity for micromolar sensing of nitric oxide [51]. Recombinant silk-elastin-like proteins (SELP), which are comprised of repeating 
motifs of silkworm silk and elastin, have also been identified as an alternative material for encapsulation of biologicals [52].

\section{Section 2: Challenges working with biomacromolecules}

Maintaining protein stability during production and storage is critical, and measures of biological activity are a critical component of this assessment. In practice, however, using biological activity as the sole parameter for defining stability is inadequate. Many sources of protein instability, such as disruption of structure or chemical modifications, can directly or indirectly impact function [53-56]. For example, chemical modification of a single residue may leave a protein susceptible to aggregation, which could negatively impact biological activity during storage or safety upon administration. Changes in a protein product are undesirable, even if those changes do not ultimately impact biological activity. For example, even subtle changes in structure carry the risk of triggering an immune response [57-60]. Therefore, demonstrating process control and batch-to-batch consistency when formulating silk-based stabilization constructs are critical for managing risk associated with potentially increased immunogenicity.

Aspects of protein stability can be divided into two primary categories, physical and chemical. Physical stability generally pertains to non-covalent modifications which lead to changes in secondary, tertiary, or quaternary structure of proteins. Chemical stability refers to covalent primary structure modifications. Many excellent reviews have been published on protein stability, stabilization strategies, stability characterization tools, and forced degradation studies [59-62]. This section will highlight the most common and critical issues pertinent to these topics, providing insight to stresses that silk can protect against.

\section{Stress factors that cause instability}

Storing a protein therapeutic at relatively high concentration in a highly purified state for extended periods of time leaves it susceptible to degradation. Beyond storage, proteins are exposed to a wide range of stresses during production and handling (Table 2).

Table 1. Potential stress factors that may be detrimental to protein stability [59, 63, 64].

\begin{tabular}{|c|c|c|}
\hline Stress factor & Example of exposure & Potential impact \\
\hline $\begin{array}{l}\text { Elevated } \\
\text { temperature }\end{array}$ & $\begin{array}{l}\text { - } \text { Improper shipment } \\
\text { - } \quad \text { Storage or handling deviation } \\
\text { - } \quad \text { Specific production process }\end{array}$ & $\begin{array}{l}\text { Partial unfolding, } \\
\text { aggregation } \\
\text { - Increased chemical } \\
\text { degradation rates }\end{array}$ \\
\hline Freezing/thawing & $\begin{array}{l}\text { - Storage of frozen bulk } \\
\text { solutions } \\
\text { - Accidental freezing during } \\
\text { shipment or storage } \\
\text { - Lyophilization }\end{array}$ & $\begin{array}{l}\text { High concentration of } \\
\text { protein or solvents in } \\
\text { freeze-concentrated } \\
\text { unfrozen fraction } \\
\text { - Structural changes from } \\
\text { crystal formation }\end{array}$ \\
\hline $\begin{array}{l}\text { Mechanical } \\
\text { stress }\end{array}$ & $\begin{array}{l}\text { - Pumping, filtration, stirring } \\
\text { during production } \\
\text { - Agitation during shipment and } \\
\text { handling }\end{array}$ & $\begin{array}{l}\text { - Shearing } \\
\text { - Interfacial effects } \\
\text { - Cavitation } \\
\text { - } \quad \text { Local thermal effects }\end{array}$ \\
\hline
\end{tabular}




\begin{tabular}{|c|c|c|}
\hline Light & $\begin{array}{l}\text { - } \text { Daylight } \\
\text { - Artificial light in production }\end{array}$ & $\begin{array}{ll}\text { - } & \text { Oxidative stress } \\
\text { - } & \text { Modification of susceptible } \\
& \text { residues } \\
\text { - } & \text { Modification of solvent }\end{array}$ \\
\hline Oxidative stress & $\begin{array}{l}\text { - Contact with oxygen (air, } \\
\text { dissolved) } \\
\text { - Impurities (excipient, leached } \\
\text { metals) } \\
\text { - Light } \\
\text { - Cavitation } \\
\text { - Vaporized sanitation agents } \\
\end{array}$ & $\begin{array}{ll}\text { - } & \text { Oxidation of susceptible } \\
\text { residues } \\
\text { - } \\
\text { - } \\
\text { Impdification to structure } \\
\text { propensity }\end{array}$ \\
\hline $\mathrm{pH}$ changes & $\begin{array}{ll}\text { - } & \text { Purification } \\
\text { - } & \text { Freezing } \\
\text { - } & \text { Formulation } \\
\text { - } & \text { Dilution into infusion liquids } \\
\end{array}$ & $\begin{array}{l}\text { - Protein conformation } \\
\text { - Solution energetics }\end{array}$ \\
\hline Dehydration & - Lyophilization & \begin{tabular}{|l} 
- $\begin{array}{l}\text { Hydrophobic/hydrophilic } \\
\text { interaction which } \\
\text { contribute to native } \\
\text { conformation }\end{array}$ \\
\end{tabular} \\
\hline Interfaces & $\begin{array}{ll}\text { - } & \text { Air-water interfaces } \\
\text { - } & \text { Filters } \\
\text { - } & \text { Primary packaging materials } \\
\end{array}$ & $\begin{array}{l}\text { - } \begin{array}{l}\text { Surface induced } \\
\text { denaturation }\end{array} \\
\text { d }\end{array}$ \\
\hline
\end{tabular}

Protein therapeutics exposed to a wide range of operations and factors can result in instability, and strategies are required to mitigate these risk factors. Typically, this strategy involves identification of the most impactful stress factors for a given biomacromolecule, and a robust formulation for the final protein product that mitigates the determined stress factors. The latter step is where silk can play a key role during handling, processing, and storage.

\section{Physical stability}

Physical stability is typically described as a change in secondary, tertiary, or quaternary structure of a protein without affecting the covalent bonds. Physical instability can lead to a variety of problems: denaturation, solvent exposure of labile residues, adsorption to surfaces, selfassociation, precipitation and aggregation [59, 60,65]. Of these degradation products, aggregation is particularly concerning in a therapeutic context for its potential for immunogenicity and impact on efficacy [65]. It is generally accepted that there are two key factors involved in protein physical stability, structural or conformational stability and solution energetics.

\section{Structural stability}

Protein native structure is the result of a variety of weak and opposing forces. The major driving force for stabilization of the folded state is the inherent desire for the system to reside at the lowest energy state [66]. The primary destabilizing force is the increased entropy present in the unfolded state. Protein conformational stability is dictated by a combination of amino acid sequence, solution variables (e.g., $\mathrm{pH}$ and ionic strength) and interaction with ligands [66, 67]. 
Stabilization is a result of many inter-atomic forces, including the hydrophobic effect, ion pairs or salt bridges, electrostatic dipoles, Van der Waals interactions, and hydrogen boding [68]. Each of these reactions is relatively weak, and a combination of a large number of them leads to stabilization of the native state. Some protein aggregates form through a partially unfolded, aggregate-prone intermediate [69, 70]. These intermediates are prone to aggregation due to exposure of hydrophobic residues or regions typically buried within the protein core. By maximizing the difference in energy between the folded and unfolded states, the probability of populating the aggregate prone intermediate state can be decreased.

\section{Solution energetics}

The second major component of protein physical stability is solution energetics, often referred to as "colloidal stability." Solution energetics is a description of protein-protein, protein-surface, and protein-solvent interactions $[68,70,71]$. These interactions are governed by the same weak forces that contribute to the native protein structure. Solution energetics is a critical component of physical stability regardless of the conformational state of the protein. Solution energetics have historically been evaluated as excluded volume effects and preferential interaction parameters such as the second virial coefficient [71-76]. More recently it has become apparent that net surface charge and surface charge distribution of proteins are critical factors influencing the second virial coefficient and solution energetics. For example, it was shown that less uniform surface charge distribution favored self-association and increased viscosity at high antibody concentrations [76]. Understanding the relationships between surface charge characteristics and protein physical stability is currently an active field of research [76-79].

\section{Mitigation of physical instability}

Solution conditions directly impact protein structural stability and solution energetics [68, 80]. Solution $\mathrm{pH}$, ionic strength, and buffer species can all affect the weak interactions responsible for protein conformational stability and protein-protein interactions. Solution $\mathrm{pH}$ alters the net charge of the protein and the surface charge distribution by changing the charges of individual groups $[58,76]$. Changes in ionic strength impact shielding effects of charged residues. The buffer species is also a critical parameter because of differences in ionization state based on the $\mathrm{pH}$ and $\mathrm{pK}_{\mathrm{a}}$, which could impact how a given buffer interacts with the protein [81-83]. Recently, alternative buffering strategies involving the use of displaced buffers have been effective at improving physical stability of proteins $[84,85]$.

The native state of a protein can also be stabilized by sugars, such as sucrose, glucose, lactose, and trehalose, at relatively high concentrations through the preferential exclusion mechanism driven by excluded volume effects [86, 87]. In addition to sugars, polyethylene glycol and glycerol have also been shown to stabilize proteins through preferential exclusion mechanisms driven, in contrast, by steric hindrance [86, 88, 89]. A second class of molecules referred to as neutral crowders retards protein aggregation through a modified preferential exclusion mechanism. Neutral crowders, such as arginine, are preferentially excluded from the gap that forms as two molecules associate. This exclusion increases the free energy of the partially associated intermediate, slowing protein-protein interaction [90, 91]. Preferential exclusion will be discussed further in the subsequent section. 
Surfactants are used to directly improve protein physical stability by shielding exposure of hydrophobic surfaces, preventing interfacial denaturation and protein-protein association through exposed hydrophobic domains. The most commonly used surfactants, polysorbate 20 and polysorbate 80, are amphipathic, non-ionic molecules composed of fatty acid esters of polyoxyethylene sorbitan [92]. Silk, which is very hydrophobic in nature, has the ability to shield exposed hydrophobic domains. This feature will also be discussed further in the subsequent section.

\section{Chemical stability}

Multiple amino acid residues can undergo chemical modification or damage [61]. Chemical modifications have been linked to altered function and decreased physical stability of proteins [53-56]. A detailed understanding of chemical degradation pathways is required to identify and mitigate these instabilities. A summary of protein chemical modifications can be found in Table 1 .

Table 2. Protein chemical modification summary. $[54,61,93]$

\begin{tabular}{|l|l|l|}
\hline Reaction type & Reaction & References \\
\hline \multirow{3}{*}{ Hydrolytic reactions } & Deamidation & {$[94-96][97]$} \\
\cline { 2 - 3 } & Isomerization & {$[56,98,99]$} \\
\cline { 2 - 3 } & Proteolysis & {$[61,100]$} \\
\hline \multirow{2}{*}{ N-terminal cyclization reactions } & Diketopiperazine formation & {$[101]$} \\
\cline { 2 - 3 } & Pyroglutamic acid formation & {$[102]$} \\
\hline Oxidation reactions & Metal-catalyzed oxidation & {$[103,104]$} \\
\cline { 2 - 3 } & Free-radical oxidation & {$[103,105$,} \\
& & $106]$ \\
\cline { 2 - 3 } & Photooxidation & {$[107,108]$} \\
\hline Condensation reactions & Dehydration synthesis & {$[109,110]$} \\
\hline
\end{tabular}

Of the reactions listed in Table 1, deamidation and oxidation are the most common. Deamidation is a non-enzymatic reaction occurring primarily at asparagine residues [97]. Deamidation of asparagine modifies the side chain to produce aspartate and isoaspartate with a loss of ammonia. Under slightly acidic to basic conditions $(\mathrm{pH}>5)$ the deamidation reactions occurs through a cyclic imide pathway [111]. A direct hydrolysis reaction under acidic conditions $(\mathrm{pH}<4)$ also occurs to form aspartate, but is typically less relevant in therapeutic protein development [111113]. Deamidation is concerning due to its ability to disrupt local protein structure [114]. Both products of asparagine deamidation can be disruptive to protein structural stability. Replacing asparagine with aspartate introduces a charged residue in place of a neutral one, while the conversion to isoaspartate introduces a methylene group into the peptide backbone.

Oxidation is a covalent modification, most often affecting methionine residues, but all residues with aromatic or sulfur containing side chains are susceptible. The primary methionine oxidation reaction results in the addition of one oxygen $(+16 \mathrm{Da})$ to form methionine sulfoxide. There are three distinct oxidative degradation pathways: metal-catalyzed oxidation, photooxidation, and free-radical oxidation $[115,116]$. Like deamidation, oxidation reactions can serve to decrease structural stability and impact aggregation propensity $[53,117]$. Methionine oxidation 
significantly reduces the side chain's hydrophobicity, potentially altering the local threedimensional structure, or directly impacting hydrophobic protein-protein interactions.

\section{Mitigation of chemical instability}

Mitigation strategies to address the chemical instability identified for a given protein must be tailored to that protein. The primary mitigation strategy is to identify solution conditions $(\mathrm{pH}$, buffer species, ionic strength, excipients) that minimize the degradation rate. For example, formulating a protein in a non-phosphate, slightly acidic buffer can minimize deamidation rates [118]. However, as $\mathrm{pH}$ is decreased to retard deamidation, the rates of isomerization of susceptible aspartyl residues increase [118]. Examples where solution conditions alone are not sufficient to mitigate all modes of chemical degradation are common. In this situation, a useful approach is to minimize the chemical instability that exudes the greatest impact on biological activity or protein conformational stability. Beyond altering solution conditions, the use of generally regarded as safe (GRAS) excipients is common practice to help control chemical instabilities. Two common classes of excipients used are chelators to help control metal catalyzed reactions, and antioxidants, such as methionine, to reduce protein oxidation $[115,116$, 119]. Replacement of oxygen with nitrogen in the headspace of vials or the use of amber vials are solutions to help control oxidation [57]. Mutagenesis can also be employed to eliminate labile residues. This approach, however, is often not straight-forward due to the potential for unintended negative consequences on protein structure and physical stability [76, 120].

Given these degradation pathways, the instability risk from structural modifications resulting from chemical instability can be decreased through a simple entrapment mechanism. From a chemical modification aspect, thus far no studies have demonstrated that silk can directly improve chemical stability of proteins, as silk is not known to be a chelator or free-radical scavenger. However, this does not exclude the possibility of silk protection from such stresses. In the following section, a discussion of stabilization mechanisms will be discussed that may lend insight into the possible mechanisms that may further describe precisely what silk can protect against.

\section{Solid state stabilization}

Due to the relative manufacturing simplicity and lower development/operational cost, liquid formulations are the preferred drug product presentation. Protein therapeutics often cannot be stabilized sufficiently in solution, even at refrigerated temperatures, to provide a clinically or commercially viable shelf-life. When this happens, stabilization in the solid state either through freezing or lyophilization is an option. Both freezing and lyophilization dramatically decrease molecular mobility [27, 121]. With little to no mobility, the chemical degradation pathways described previously become impaired, and structural stability is maintained [27, 121].

The processes of freezing or lyophilization are themselves significant stresses to a protein, often inducing physical instability. To mitigate this risk, excipients that remain amorphous in the solid state are added to the formulation. Molecules which remain amorphous in the freeze-dried state allow for hydrogen bonding with the protein when water is removed, helping to stabilize protein structure [122]. For lyophilization specifically, amorphous molecules do not provide much physical structure to the solid cake, often collapsing and making the removal of water impractically slow or even impossible. To combat this, molecules which take on a crystalline 
structure during freezing are often added. Crystalline excipients provide the cake structure and allow for more rapid and efficient sublimation [27]. Caution must be taken as crystalline structure in the solid phase can destabilize protein structure. Even in the lyophilized state, proteins are still typically stored under refrigerated conditions in order to maintain long-term stability. Solid state stabilization benefits from developing excipients that can improve storage stability to the point of eliminating the cold chain requirement.
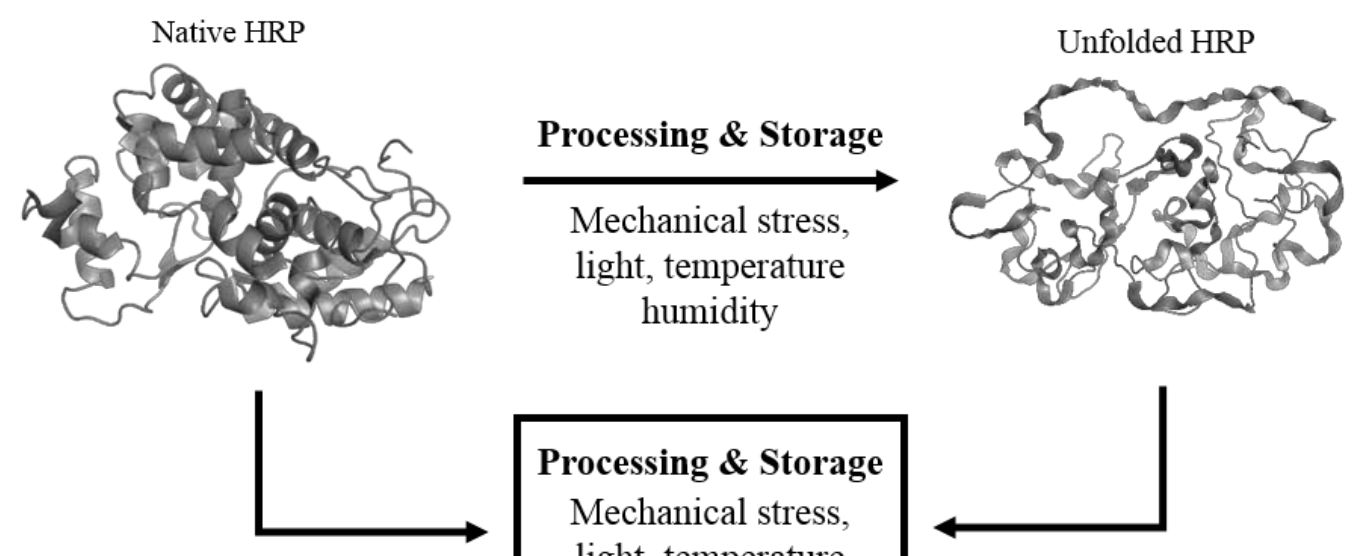
Processing \& Storage
Mechanical stress, light, temperature humidity
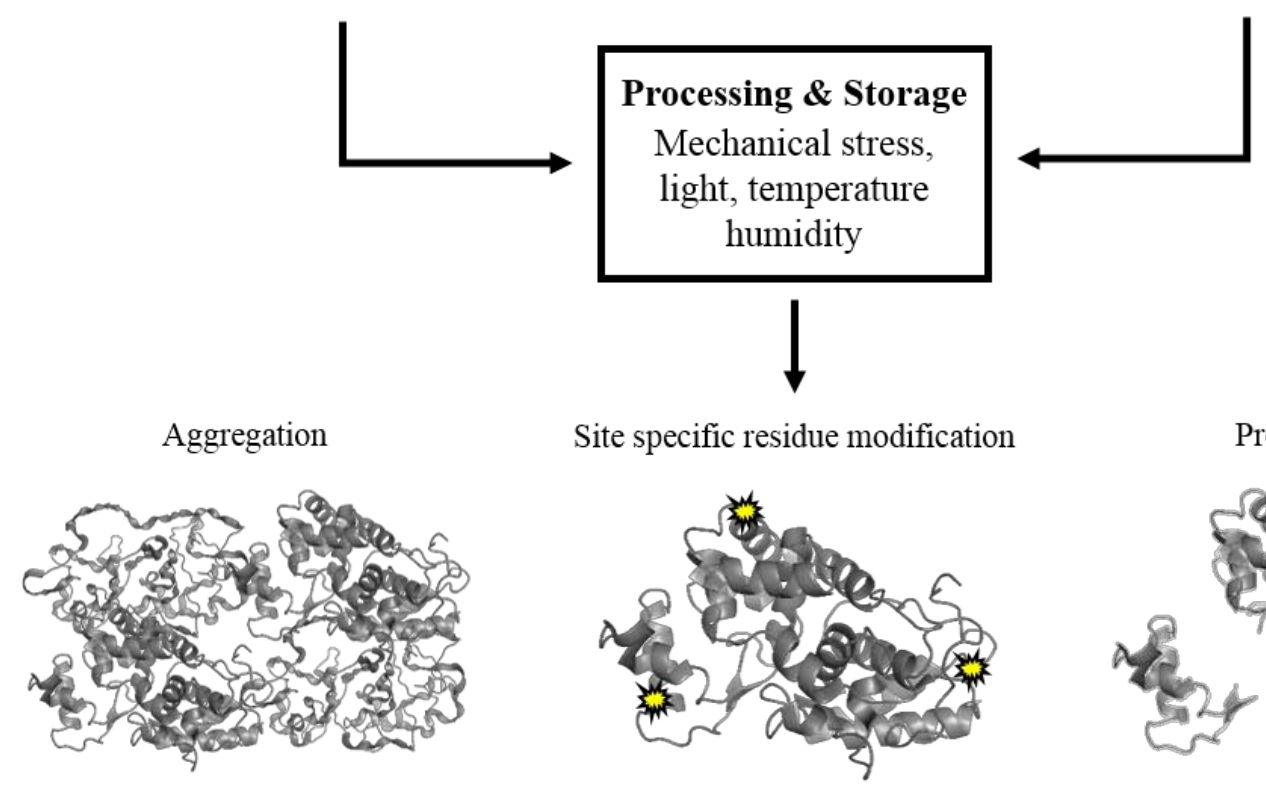

Fig. 1. Modes of protein degradation that can occur during processing and storage. Horseradish peroxidase (HRP) was chosen as a model protein. Protein visualizations were obtained using PyMOL with protein identifiers from the protein database managed by the Research Collaboratory for Structural Bioinformatics (RCSB PDB). Adapted from [123] and [124].

\section{Section 3: Mechanisms of Silk-Based Stabilization}

Although silk has demonstrated stabilizing ability, and protein degradation pathways have been extensively characterized, the underlying mechanism of stabilization of silk that connect the two findings has not been fully elucidated. Without a more complete understanding of the stabilization mechanisms for labile compounds in silk, empirical approaches are utilized to define the best formulations for a particular protein for silk stabilization matrices. Therefore, the focus of this section is on the major hypotheses used to explain the effectiveness of silk as a stabilizer in both the liquid and solid states, and to critically evaluate the ability to provide fundamental insight into the stabilization process. 


\section{Mechanisms of Stabilization in the Liquid State}

One mechanism, preferential exclusion, has traditionally been used to explain protein stability in the liquid state [86]. Typically, however, this mechanism has held true for sugar based stabilization systems. Silk's unique structure has led to systems that exhibit interactions which demonstrate potential alternative mechanisms for protein stabilization. The fact that silk's stabilizing behavior cannot be explained through a single mechanism demonstrates that at any given time, a combination of these mechanisms may be at play. The exact combination of mechanisms would be based on the structure and surface chemistry of the analyte, and thus renders silk a highly versatile stabilizer. To this end, we review the applicability of the preferential exclusion hypothesis, and also the effects of shielded hydrophobic and surface charged domains.

\section{Preferential Exclusion}

One of the most widely accepted protein stabilization mechanisms in the liquid state involves thermodynamic stabilization of the native structure of a protein by preferential interaction. This phenomenon has been extensively characterized [71]. Briefly, it was found that cosolvents that have long been used as stabilizers were preferentially excluded from the protein surface. In other words, the protein is contained within a shell of water, which is surrounded by a cosolventenriched bulk fluid. Through this newly formed concentration gradient, the free energy of the system is increased. If the protein were to unfold, the exposed surface area would further increase, thus requiring a larger zone of preferential exclusion. According to Le Chatelier's principle [125], however, all systems favor the state with lowest free energy. This tendency drives equilibrium towards the smallest zone of preferential exclusion, which is achieved by the native protein structure. The dominant source of preferential exclusion arises from steric exclusion, or excluded volume effects $[88,126]$. This phenomenon results from the difference in size between water and cosolvent molecules. Because no two molecules can occupy the same space at the same time, and the cosolvent molecule is generally larger than the water molecule, there is a region around the protein in which only water can enter. Thus, a cosolvent concentration gradient between the aqueous shell surrounding the protein and the bulk cosolvent rich fluid is forged, ultimately providing a thermodynamically unfavorable transition from native to denatured protein.

Based on these findings, and the relatively large size of soluble silk fragments, it is reasonable that silk can exhibit significant steric exclusion on proteins in solution. This hypothesis can be supported by the study where glucose oxidase (GOx) stability was assessed in phosphate buffered saline (PBS) and also silk solutions. It was found that solutions with a silk concentration of $10 \mathrm{mg} / \mathrm{mL}$ possessed the ability to increase the half-life of GOx to 877 days in silk from 14 days in PBS and 74 days in a $1 \mathrm{mg} / \mathrm{mL}$ silk solution [36].

\section{Hydrophobic and Electrostatic Binding}

The results of the GOx stabilization in solution could also be explained by the presence of hydrophobic regions within the silk protein. Physical stability can be improved by shielding hydrophobic domains, stabilizing the native state, and mitigating unwanted protein-protein interactions. Several properties of silk can make it highly effective at reducing physical instability pathways that occur via the mechanisms described in Section 3. 
First, silk's amphiphilic nature allows for shielding of exposed hydrophobic patches, in a manner similar to that described for surfactants. Second, the high degree of hydrophobicity leads to strong attraction to exposed hydrophobic domains or strong repulsion from exposed hydrophilic domains. The strong attraction can positively impact hydrophobic domain shielding, while the strong repulsion can lead to native state stabilization through preferential exclusion. Finally, the silk molecule is highly charged, meaning that through interaction with protein surfaces it can alter exposed surface charge distribution, changing protein-protein interaction propensity.

It was found that the release of monoclonal antibodies was directly related to the inhibition of hydrophobic interactions through the presence of surfactant [119]. It was also found that the release of stromal cell-derived factor 1 (CXCL12) was directly related to modulation of the surface charge of silk [127]. Taken together, the dose dependency of GOx stability, and use of Tween and charge modulation to improve recovery suggests that some combination of steric exclusion, hydrophobic interactions, and electrostatic interactions play a role in stabilization in the liquid state.

\section{Mechanisms of Stabilization in the Solid State}

Historically, two hypotheses have been used to explain the stabilizing features of glassy materials in the dried state. The first is known as the "water-replacement hypothesis," and points to a thermodynamic stabilizing effect. The second, known as the "vitrification" or "glassdynamics hypothesis" points to a kinetics-controlled stabilizing effect where the dynamics of the glass matrix impede degradation processes. While both of these hypotheses have been widely cited in reference to protein stabilization, neither has provided a universal or quantitative metric for predicting protein stability in glass matrices, suggesting that there are other factors in play. More recently, several groups have also implicated an extension of the "glass-dynamics" hypothesis to be the overarching mechanism at play with regards to protein stabilization. [128]

\section{Water Replacement Hypothesis}

One of the two competing theories, known as the water replacement hypothesis, is based on the concept that the encapsulating matrix acts as a substitute for water. Often when water is lost, the protein will misfold due to the loss of interactions that maintain the native structure. In order to prevent protein denaturation, the glass matrix must increase the free energy of protein unfolding. In doing so, the native conformational state of the entrained protein is thermodynamically favored over the denatured state. The mechanism by which this happens has been proposed to result from replacement of hydrogen bonds lost between water and protein during the drying process, with hydrogen bonds between the stabilizing material and protein $[86,129]$. While this hypothesis has been widely cited, the evidence supporting this theory is conflicting. Based on this hypothesis, one would expect that maintenance of protein structure is the key factor in maintaining stability. It has been shown, however, that maintenance of secondary structure has not always correlated with maintenance of protein function [130]. Furthermore, current technology cannot monitor tertiary structure in the dried format, nor can it monitor thermodynamic conformation transiently [128]. Given the difficulty in affirming this theory, the water replacement hypothesis may not be the only causal factor in protein stabilization.

Nonetheless, it is hypothesized that silk would be well suited to serve as a water substitute. The raw silk fibers obtain robust mechanical strength through self-assembled $\beta$-pleated sheets that 
form both inter- and intra-molecule hydrogen bonds [131]. During solubilization of raw fibers, these hydrogen bonds are broken in order to obtain a silk solution. Upon dehydration, these hydrogen bonds reform, potentially interacting with entrained compounds [6]. Such interactions could explain results in silk-based horseradish peroxidase (HRP) stabilization studies where increased crystalline content led to a higher content of chemically entrapped HRP [30, 36].

\section{Glass Dynamics or Vitrification Hypothesis}

The other competing hypothesis, known as either the glass dynamics or vitrification hypothesis, suggests that removal of water impedes degradation reaction kinetics [132]. Through dilution of the protein into an amorphous rigid, glassy solid, molecular mobility is restricted, thus retarding instability pathways [133]. This interpretation focuses solely on the kinetics of the system in contrast to the water replacement hypothesis, which involves maintenance of the native protein structure through thermodynamic equilibrium. Because the motion of the protein becomes coupled to the motion of the matrix, relaxation processes of glass matrix formers become important with regard to prediction of stabilization.

The glass dynamics of a matrix can typically be characterized by three relaxation processes that are categorized by motions of structural motifs of varying size, occurring on various timescales. The $\alpha$-relaxation, the slowest of the motions, occurs on second or longer timescales and is often referred to as the structural relaxation. This relaxation results in the loss of secondary protein structure and is the most well-known relaxation process, analogous to the glass transition temperature, $T_{\mathrm{g}}$. Prior to the onset of the $\alpha$-relaxation comes two smaller scale relaxations, known as the $\beta$-relaxation processes. The quicker of the two $\beta$-relaxations, $\beta_{\text {fast }}$-relaxation, occurs on the picosecond timescale, and corresponds to atomic fluctuations and vibrations, including motions of structures such as polymer side-chains and terminal-arms [134]. The slower of the two $\beta$-relaxations occurs on the microsecond to millisecond timescale, and is known as the Johari-Goldstein $\beta$-relaxation $\left(\beta_{\mathrm{IG}}\right)$. This relaxation represents intermolecular motions found on the scale between the $\alpha$-relaxation and the $\beta_{\text {fast }}$-relaxation processes. Examples include $\alpha$-helix or protein subunit motions [135].

Historically, formulation scientists have attempted to correlate $\alpha$-dynamics to degradation rates of entrained proteins [136]. The relaxation is most commonly quantified through the WilliamsLandel-Ferry relation, which shows that $\log \left(\tau_{\alpha}\right)$ scales with $\left(\mathrm{T}_{\mathrm{g}}-\mathrm{T}\right)$, where $\tau_{\alpha}$ is the $\alpha$-relaxation time, and $T_{g}$ is the glass transition temperature of the matrix [137]. The ubiquity of thermoanalytical techniques such as differential scanning calorimetry provides the easiest and most rapid material relaxation characterization. While some studies have shown positive correlation between $\mathrm{T}_{\mathrm{g}}$ and degradation rates [138], a recent study showed the contrary for over 100 different glass forming matrix formulations [139]. Thus degradation rates correlate with $\tau_{\alpha}$ within a given glass system, but cannot be used to compare stability between glass systems [139, 140].

Recently, fast relaxation processes have emerged as important factors in defining the stabilizing ability of a matrix across different glass materials [139]. Alcohol dehydrogenase and horseradish peroxidase degradation rates, $\log \left(\tau_{\mathrm{d}}\right)$, correlated linearly with $\beta$-relaxation times, $\log \left(\tau_{\beta}\right)$, in over 100 plasticized and antiplasticized glasses. Furthermore, this correlation has been replicated in other studies, including those that have stabilized IgG [141], human growth hormone (hGH) 
[140], and keratinocyte growth factor-2 (KGF-2) [142]. Mechanistically, the amplitude of $\beta$ relaxation, known as the mean-squared displacement of hydrogen atoms $\left(<\mathrm{u}^{2}>\right)$, has been linked causally to decreases in the diffusion coefficient of the matrix. Ultimately, by reducing the nanoscopic pore-space within a matrix, the diffusion of reactive small molecules was retarded, ultimately limiting degradation processes [143, 144]. Furthermore, this reduction can also suppress movement of high-mobility protein moieties, preventing the protein from unfolding [145].

Reduction of molecular mobility has been demonstrated in several cases of silk-based stabilization. The $\mathrm{T}_{\mathrm{g}}$ of MMR vaccine was increased from $68.9^{\circ} \mathrm{C}$ to $89.2^{\circ} \mathrm{C}$ when mixed with silk solution [38]. This enhanced thermal stability decreases the overall molecular mobility and thus supports the glassy dynamics hypothesis. While this result does not examine the faster relaxation processes, it stands to reason that future studies could demonstrate results correlating stability and $\beta$-relaxation. HRP stabilization studies further support the glassy dynamics hypothesis, where it was shown that samples with higher crystalline fraction resulted in higher maintenance of HRP activity [30]. Increased crystalline fraction was found to decrease $\tau_{\beta}[146]$, indicating that decreased mobility is important in the stabilizing ability of the silk protein.

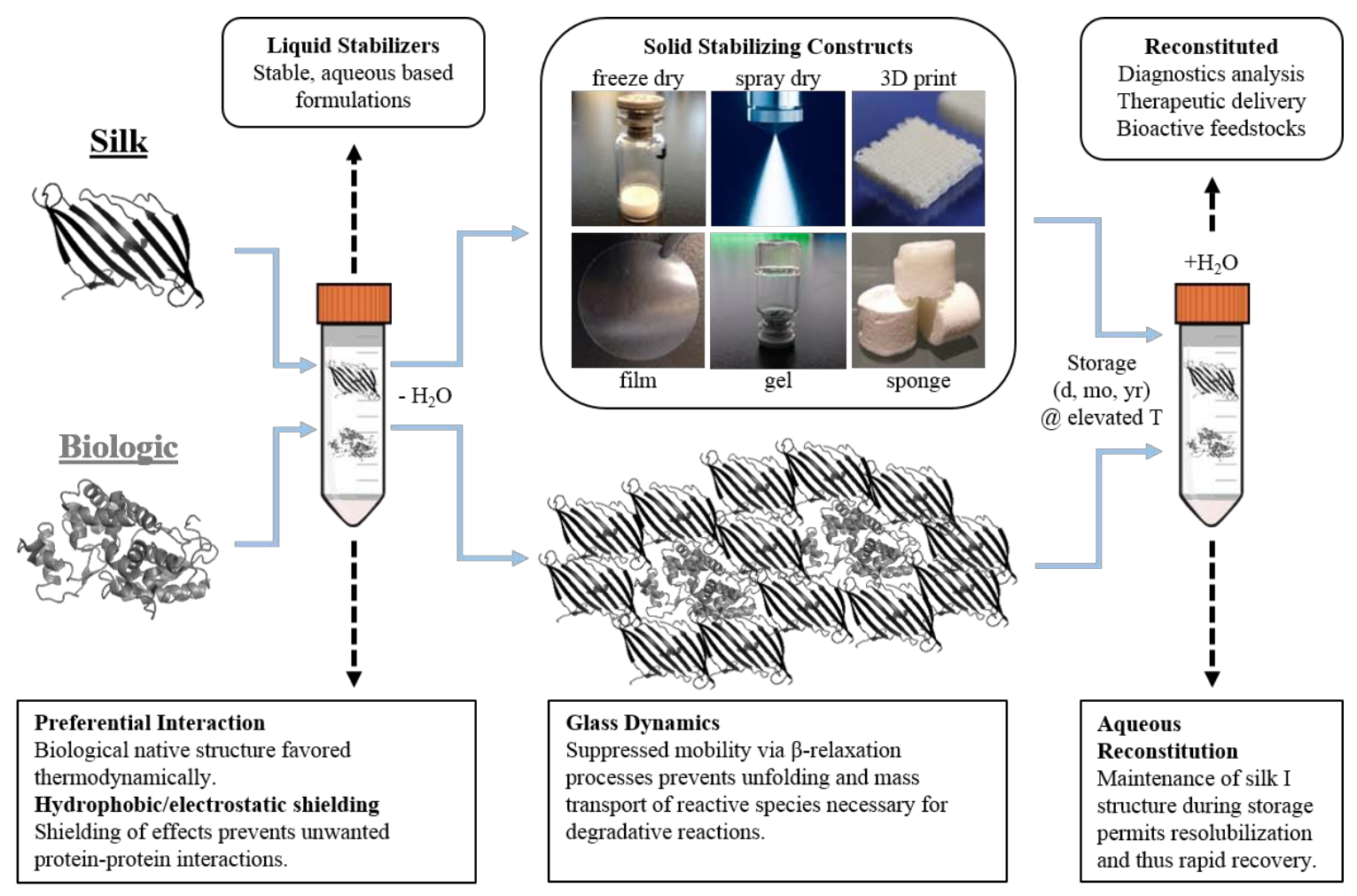

Fig. 2. Schematic of silk-based stabilization materials and systems processing with accompanying mechanisms of stabilization.

\section{Section 4: Mechanistic bases for release and recovery}

Herein, we review the practical considerations when fabricating dried silk constructs for stabilization and also the mechanistic interactions that have been modulated to influence release of entrained proteins from silk. Given this review, we also expect that these interactions would 
modulate stability through the mechanisms discussed in section 3. Specifically, we will review four aspects that can be engineered to aid in recovery and stability. These topics include considerations for silk construct fabrication, silk formulation, encapsulated analyte properties, and release media. We also reference liquid silk-protein stabilization findings to highlight additional stabilization mechanisms in formulations ultimately designed for solidification.

\section{Silk construct entrapment}

The most commonly employed method of entrapment with silk has been bulk-loading of the compound of interest. Alternative silk entrapment techniques include adsorption of protein on to the silk construct [147], covalent attachment through chemical modification [131], and encapsulation of protein into micro- or nanospheres [148]. In this section, we focus on two methods that allow for rapid recovery, bulk-loaded air-dried films and lyophilized cakes. The emphasis in this section is in the practical elements of solid formulation of silk materials to ensure a high quality or efficient solidification process.

\section{Silk film considerations}

The majority of silk stabilization experiments have involved silk and biological mixtures that are cast onto surfaces and allowed to air-dry. Dehydration in this fashion retains the predominantly random coil silk I structure, which is the conformation of the protein as stored in silkworm glands [149]. These films retain water solubility, and can be reconstituted, allowing for rapid recovery of entrapped analytes [150]. To tailor these construct for drug delivery, the films can be rendered insoluble through alteration of secondary structure from silk I to $\beta$-sheet (silk II). Nonaqueous solvents including hexafluoroisopropanol and formic acid can be used to dissolve crystalline silk films but may lead to damage or denaturation of incorporated compounds. When casting silk films, important practical factors in retaining water solubility are the molecular weight of silk [21], and thickness of construct [151], which can be modified by surface area of the casting substrate, concentration of silk solution, casting volume, drying rate [152].

One other consideration for maximizing protein recovery from air-dried silk films involves the so-called "coffee ring effect," or the formation of a highly concentrated protein ring around the perimeter of a dried construct. The mechanism of this phenomenon stems from capillary flow [153]. Because the contact line between the liquid and drying surface is pinned, the liquid that evaporates at the edge of the drop must be replenished by the liquid from the center of the drop. Ultimately, this phenomenon results in an insoluble edge and soluble center. Punching out a subsection of the master film from the center avoids the issue of incomplete solubility.

\section{Silk lyophilization considerations}

Recently, silk has been used as an excipient or solid carrier in lyophilization formulations [38, $119,154]$. In order to prevent protein denaturation during lyophilization, it is important to understand the changes that may occur during the freezing and drying processes. One of the most important considerations is maintenance of cake structure integrity, which can be achieved by maximally freezing the matrix surrounding the ice crystals. Collapse can be prevented by ensuring that the primary drying temperature is below both the eutectic $\left(\mathrm{T}_{\mathrm{e}}\right)$ and glass transition temperatures $\left(\mathrm{T}_{\mathrm{g}}{ }^{\prime}\right)$. [155] The former represents the temperature at which liquid begins to appear in the frozen fraction. The latter represents the temperature at which the frozen mixture gains enough thermal energy to allow for diffusion of molecules along the matrix, thereby 
transforming from a hard and brittle glass to a softened one [156]. As mentioned previously, the $\mathrm{T}_{\mathrm{g}}$ ' of silk occurs at approximately $-11^{\circ} \mathrm{C}[28]$, while the $\mathrm{T}_{\mathrm{e}}$ occurs at approximately $-4^{\circ} \mathrm{C}$.

Another important consideration is the buffer system employed in the formulation. Many biologicals require the use of phosphate buffers to maintain stability in the liquid state. However, phosphate buffered solutions have demonstrated acidification shifts of over $3 \mathrm{pH}$ units during the freezing process due to crystallization of the sodium salt [121]. This effect may not only be damaging to the entrapped protein, but also to the silk matrix, which has been shown to undergo accelerated gelation at low $\mathrm{pH}$ [16]. Therefore it is critical to use buffers such as histidine, citrate, or Tris that resist $\mathrm{pH}$ shifts upon freezing. These and other generic lyophilization considerations are reviewed elsewhere [29], many of which apply to the use of mixtures of silk with various other excipients or buffer systems.

\section{Silk specific strategies for optimal release}

Numerous processing conditions have been examined with purified silk that demonstrate a wide range of tunable properties. In this section, we discuss the strategies most useful for maximizing release of silk from the entrained analyte.

\section{Molecular Weight}

As discussed earlier, during silk purification, cocoon fibers are boiled in an alkaline solution to strip the fibroin protein from sericin, a glue-like protein that is spun simultaneously with the fibroin. Prolonged exposure of fibroin to these conditions results in hydrolytic degradation of silk fibers into smaller fragments [14, 157]. Silk fibroin extracted for 10 minutes had a molecular weight range of $171 \mathrm{kDa}$ to $490 \mathrm{kDa}$, for 30 minutes from $31 \mathrm{kDa}$ to $268 \mathrm{kDa}$, for 60 minutes $<$ $171 \mathrm{kDa}$, and for 90 minutes $<71 \mathrm{kDa}[15,158]$. Lower molecular weight silk used for capping reservoirs of various compounds including indigo carmine, rifampicin, azoalbumin, and reactivered 120, allowed for more rapid and complete release [158]. Beyond degumming time, alternative strategies for further decreasing molecular weight include autoclaving [159], selective use of either heavy or light chain protein fractions [160], and enzymatic digestion [161] of silk solution prior to casting, as well as alkaline hydrolysis of degummed silk fibers [162].

\section{Density}

Inceased construct density has long been used as a strategy to delay compound release from drug delivering devices through increased tortuosity. In the context of silk, the density of the construct not only bolsters the diffusion barrier, but also decreases solvent penetration. In a mechanistic study of antibody release from lyophilized silk gels, the effect of construct density on cumulative release was examined. Constructs lyophilized from lower concentration silk solutions $(3.1 \% \mathrm{wt} / \mathrm{v})$ released $81 \%$ of antibody, while higher concentration silk solutions $(6.7 \% \mathrm{wt} / \mathrm{v})$ only released $36 \%$ of the antibody [154]. This trend was mirrored through the use of weight pressed constructs (to increase density of the silk). The mechanism of this effect was likely the result of the high density $\beta$-sheet network that leads to excluded water [163]. Empirically, this mechanism was supported through the examination of the construct swelling ratio, a parameter that defines water uptake at equilibrium. The effect of density, and by proxy hydration properties, was an important factor in the recovery process. Thus the design of dissolvable constructs with enough material to provide sufficient stabilization without compromising timely dissolution is required. 


\section{Crystallinity}

Silk assumes ordered and highly stable crystalline isoforms in the presence of sufficient solution conditions or thermophysical stimuli. In turn, stable silk structures such as $\beta$-pleated sheets allow for limited solvent penetration and thus solubility. For the purpose of releasing entrapped biomolecules, silk films can be rendered insoluble through water-annealing, methanol exposure, or the inclusion of bulk-loaded plasticizers $[30,36]$. While this processing step delays the release of many compounds [11], the induction of crystallinity can limit entrapped material recovery. This phenomenon is hypothesized to result from physical entrapment or irreversible binding between the encapsulated compound and silk. In such situations, a complete mass balance recovery can only be achieved by either proteolysis with protease XIV [164] or disruption of hydrogen bonding through the use of highly concentrated chaotropes such as urea or guanidine hydrochloride. Because both recovery methods can potentially denature the entrapped biologicals, prevention of $\beta$-sheet formation during processing and storage remains the best option for ensuring maximal recovery. Crystallinity during processing can be mitigated by avoiding excessive shear force $[165,166]$, acidic $(<4)$ and basic $(>9) \mathrm{pH}[16]$, high ionic strength, and the use of aged silk solutions (e.g., greater than 3 months old stored at $4^{\circ} \mathrm{C}$ ) [18].

\section{Chemically Modified Silks}

Purified silk has demonstrated the ability to act as a stabilizer free of any covalent modification, suggesting the role of the native structure to act as a protectant. However, the amino acid composition of silk is conducive to reactions that can result in several different modification strategies. Although the majority of silk is comprised of non-reactive amino acids glycine and alanine, silk also contains serine, threonine, aspartic acid, glutamic acid and tyrosine, which have all been modified via varying chemistries [131]. This work has been reviewed [131] and the mechanisms pertinent to stabilization will be briefly reviewed here.

Traditionally, three types of reactions have been applied in order to couple molecules to silk. Immobilizing a biologic can retain bioactivity during storage, processing, or tailoring the physicochemical properties of the scaffold for a specific application. Immobilizing a functional motif can alter the silk properties to inhibit unwanted interactions. The first reaction, cyanuric chloride-activated coupling, complexes cyanuric acid with a desired motif, which can further complex with tyrosine residues of silk. This reaction scheme has been used for PEGylation of silk, to increase hydrophilicity [167]. Carbodiimide coupling can react primary amines of biologicals to carboxylic acid side chains of aspartic acid, glutamic acid, and lysine residues within the silk sequence. Because of the ubiquity of primary amines on biologicals, this reaction pathway provides an opportunity for conjugation of bioactive molecules to silk. Through this reaction, BMP-2 [168] and HRP [169] decorated silks have been fabricated. Poly(D,L-lactic) acid (PLA) has also been coupled to silk in this manner, leading to a scaffold with decreased hydrophobicity [170]. Glutaraldehyde, a chemical crosslinker, was used to immobilize both insulin [171] and L-asparaginase [172] via conjugation with silk.

Individual amino acid modifications of arginine, tyrosine, and serine in silk have also been performed. The positive charge of arginine has been neutralized with 1,2-cyclohexanedione to form a neutral peptide [173]. This modification could be particularly useful in situations where coulombic attraction has a detrimental effect on analyte recovery. Sulfation of tyrosine and serine residues were also performed through treatment of silk fibers in a chlorosulfonic acid and 
pyridine mixture [174]. The experiment showed that the silk back-bone was hydrolyzed into $20 \mathrm{kDa}$ fragments. Tyrosine has also been modified using diazonium coupling chemistry, which is both rapid and performed under mild conditions [175]. The addition of the diazonium group allows for a wide variety of functionalization strategies, including the addition of sulfonic acid groups, which inhibit $\beta$-sheet self-assembly in silk, and also results in a more anionic silk material. Recently, copper(1) catalyzed azide-alkyne cycloaddition (CuAAC), more commonly referred to as click chemistry, has been employed to overcome the inefficiencies of carbodiimide coupling [176]. The reaction involves conjugation of diazonium coupled silk to an alkynemolecule complex via cycloaddition. Because CuAAC is highly specific with respect to protein coupling, unwanted covalent crosslinking between the biologic molecules or between the silk molecules is unlikely. This prevents potentially immunogenic responses resulting from the aggregates. FGF-2 has been coupled to silk using click chemistry [176].

\section{Analyte specific}

While it is unlikely that the analyte can be customized for optimal recovery, it is still valuable to know a priori whether or not that analyte will have issues with entrapment in silk matrices. As such, we review the mechanistic studies in which modulation of protein physicochemical interactions has resulted in different behaviors when encapsulated in silk.

\section{Charge}

The charge of an analyte can have a significant effect on recovery from silk. When a set of synthetic dyes were released from silk films, the dye diffusion coefficients were compared to various physicochemical properties [177]. While diffusion proved to be the primary release mechanism, dyes carrying a higher negative charge had higher diffusion coefficients, indicating that electrostatic repulsion was driving release. The opposite effect was observed when the positive charge of stromal cell-derived factor 1 (CXCL12) [127] was implicated as a mode of binding to silk that led to reduced release. This result was shown through comparison of release of the proteins from silk processed with and without sulfonic acid functionalization. The latter, which carries significantly more negative charge, delayed the burst release from silk hydrogels through electrostatic interactions. Charge was also implicated as an interaction mechanism for FGF-2 [178], alcian blue, rhodamine B, and crystal violet [179].

\section{Analyte Molecular Weight}

Size affects diffusion and thus release of proteins from polymer systems [180]. Fluorescein-isothio-cyanate (FITC) labeled dextrans of varying molecular weight were used to correlate the effect of size on release from air dried silk films. Because of the thickness of these films, the constructs were insoluble as fabricated, and were further treated with methanol to induce more crystallinity. The smallest dextrans, $4 \mathrm{kDa}$, eluted $86 \%$, while the largest, $40 \mathrm{kDa}$, cumulatively released 14\% from silk films as fabricated. This trend was attributed the decrease in diffusivity, caused by loss of free diffusion path. The effect of protein molecular weight may be twofold in the context of silk, as larger macromolecules will have more exposed motifs that can bind and entangle with the silk matrix.

\section{Variable release media strategies}

Beyond modulation of silk purification processing techniques, release media represents another avenue for optimization of recovery upon reconstitution. Through the use of different buffers, 
salts, surfactants, and enzymes, various interactions have been disrupted to increase the kinetics of release.

\section{Hydrophobicity}

Hydrophobicity is a property exhibited by the silk protein. In order to determine the parameters controlling release and recovery of antibody, the effects of release media on a formulation of lyophilized silk-antibody sonication induced gels was studied. The results demonstrated that the addition of polysorbate 80, a surfactant known to disrupt hydrophobic interactions, disrupted hydrophobic $\beta$-sheet interactions. In turn, matrix hydration was facilitated, ultimately increasing antibody recovery [119]. Combined with the ability to fractionate silk into hydrophobic and hydrophilic segments via $\alpha$-chymotrypsin [161], there are multiple strategies to modulate silk and entrapped protein hydrophobic interactions.

\section{Ionic Interactions}

Ionic interactions have also been implicated to play a secondary role in biologic release. To disrupt the interactions between antibody and silk, both ionic strength and $\mathrm{pH}$ were modulated. The isoelectric points of silk and the antibody are 4.5, and 5.0, respectively. Because the complex was formulated at physiological $\mathrm{pH}$, both molecules carried negative charges. At various levels of sodium chloride in the release media, antibody recovery and release decreased from $40 \%$, at $150 \mathrm{mM}$, to below $10 \%$, at $3.0 \mathrm{M}$. The mechanism of this phenomenon results from shielding of ionic repulsion, thus reducing hydrophobic attraction from retaining the antibody. At low $\mathrm{pH}$ (4.0), where charges were neutralized due to proximity to $\mathrm{pI}$, low cumulative release was observed at $<5 \%$. Increasing the $\mathrm{pH}$ to 8.0 allowed both molecules to regain a negative charge, allowing ionic repulsion and resulting in a cumulative release of $\sim 30 \%$. Ionic strength was also shown to disrupt electrostatic interactions between protamine and silk micelles through isothermal titration calorimetry [181]. Solution $\mathrm{pH}$ has also been used to modulate release of doxorubicin from silk nanoparticles [182].

\section{Salts}

Interactions between analytes and silk also depend on the type of salt used in the release buffer. The loading of protamine and silk was studied in the presence of sodium salts with anions from the middle and extremes of the Hofmeister series. Complex coacervation between protamine and silk was greatest in the presence of sodium thiocyanate, the chaotrope, and least in the presence of sodium sulfate, a cosmotrope [181]. The mechanism of this interaction involved stabilization and destabilization of silk micelles in solution. In the presence of chaotropes, micelles are destabilized, increasing the number of free binding sites for protamine to electrostatically interact. It is important to consider salting-in or salting-out ability of salts during formulation of silk in order to optimize interactions with entrapped proteins. In addition, highly concentrated chaotropes such as $8 \mathrm{M}$ urea [183] and 6M guanidine hydrochloride [179] solutions have been employed to solubilize crystalline silk. While these formulations have resolubilized $\beta$-sheet structures, the presence of silk can have a detrimental effect on colorimetric activity, and immunoassays. Thus proper treatment of assay controls are critical, otherwise samples will need to be dialyzed prior to analysis. 


\section{Enzymatic degradation}

Incorporation of enzymes specific to the silk matrix through co-loading during formulation is also a strategy that could improve release via silk material digestion. Various enzymes have been used for this purpose. Specifically, serine proteases including, proteinase K, protease XIV, $\alpha$ chymotrypsin, collagenase, and metalloproteases including MMP-1, and MMP-2 were used to assess bulk degradation of silk films and sonication induced hydrogels [184]. Proteinase K was the only enzyme with the ability to induce significant mass loss in the silk films. Proteinase K, protease XIV and $\alpha$-chymotrypsin induced degradation in the less dense hydrogels. The more specific MMPs were only able to demonstrate degradation in the aqueous state. Avoiding overlap between primary structure enzyme cleavage sites of silk and entrained protein is critical for retaining bioactivity. 


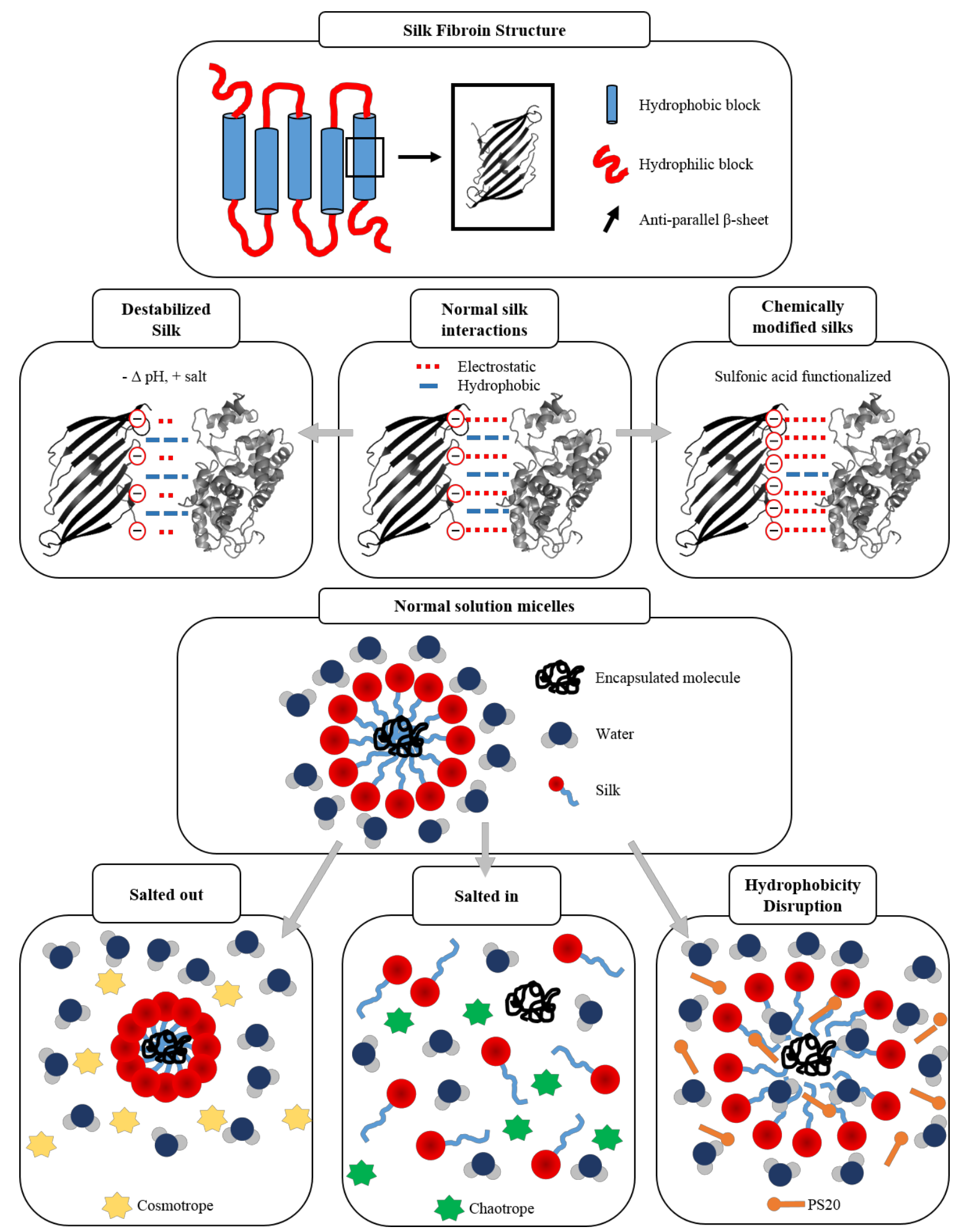

Fig. 3. Interactions between silk and entrained protein on the secondary structure scale (above) and on the quaternary structure scale, as seen in solution (below). Horseradish peroxidase was chosen as a model protein for the depictions above. Adapted from [119] and [181]. 


\section{Conclusions}

Silk possesses the ability to stabilize biomolecules. The mild and aqueous based fabrication process of silk structure modification, in addition to the thermostable nature of the protein, renders the protein polymer matrix an attractive candidate for stabilization applications. However, a more complete understanding of stabilization mechanisms for labile compounds in silk is needed to avoid empirical approaches to define the best formulations for silk stabilization matrices. As such, common protein degradation pathways during processing and storage were reviewed, in addition to the mechanisms by which silk can protect against these stresses. Accompanied by an outline of physical and chemical interactions exhibited by silk on biologicals, it is expected that rational design can be incorporated in future formulations in order to maximize the stabilization potential of silk.

\section{Acknowledgements}

We gratefully acknowledge Marcus Cicerone, Benjamin Partlow, and Jeannine Coburn for helpful discussions. We also gratefully acknowledge Rodrigo Jose and Joseph Brown for providing photographs for figures. We thank the National Institute of Health (P41 EB002520), Air Force Office of Scientific Research (FA9550-14-1-0015), and the Defense Threat Reduction Agency (HDTRA1-14-1-0061) for support of this work.

\section{$\underline{\text { References }}$}

[1] G.H. Altman, R.L. Horan, H.H. Lu, J. Moreau, I. Martin, J.C. Richmond, D.L. Kaplan, Silk matrix for tissue engineered anterior cruciate ligaments, Biomaterials, 23 (2002) 4131-4141.

[2] G.H. Altman, F. Diaz, C. Jakuba, T. Calabro, R.L. Horan, J. Chen, H. Lu, J. Richmond, D.L. Kaplan, Silk-based biomaterials, Biomaterials., 24 (2003) 401-416.

[3] F.G. Omenetto, D.L. Kaplan, New opportunities for an ancient material, Science, 329 (2010) 528-531.

[4] S.W. Hwang, H. Tao, D.H. Kim, H. Cheng, J.K. Song, E. Rill, M.A. Brenckle, B. Panilaitis, S.M. Won, Y.S. Kim, Y.M. Song, K.J. Yu, A. Ameen, R. Li, Y. Su, M. Yang, D.L. Kaplan, M.R. Zakin, M.J. Slepian, Y. Huang, F.G. Omenetto, J.A. Rogers, A physically transient form of silicon electronics, Science, 337 (2012) 1640-1644.

[5] F.G. Omenetto, D.L. KapLan, A new route for silk, Nat Photonics, 2 (2008) 641-643.

[6] X. Hu, D. Kaplan, P. Cebe, Determining beta-sheet crystallinity in fibrous proteins by thermal analysis and infrared spectroscopy, Macromolecules, 39 (2006) 6161-6170.

[7] C.Z. Zhou, F. Confalonieri, M. Jacquet, R. Perasso, Z.G. Li, J. Janin, Silk fibroin: Structural implications of a remarkable amino acid sequence, Proteins-Structure Function and Genetics, 44 (2001) 119-122.

[8] T. Arai, G. Freddi, R. Innocenti, M. Tsukada, Biodegradation of Bombyx mori silk fibroin fibers and films, J Appl Polym Sci, 91 (2004) 2383-2390. 
[9] K. Numata, D.L. Kaplan, Silk-based delivery systems of bioactive molecules, Advanced drug delivery reviews, 62 (2010) 1497-1508.

[10] T. Yucel, M.L. Lovett, D.L. Kaplan, Silk-based biomaterials for sustained drug delivery, Journal of controlled release : official journal of the Controlled Release Society, 190 (2014) 381397.

[11] E.M. Pritchard, D.L. Kaplan, Silk fibroin biomaterials for controlled release drug delivery, Expert opinion on drug delivery, 8 (2011) 797-811.

[12] E.M. Pritchard, P.B. Dennis, F. Omenetto, R.R. Naik, D.L. Kaplan, Review physical and chemical aspects of stabilization of compounds in silk, Biopolymers, 97 (2012) 479-498.

[13] D.N. Rockwood, R.C. Preda, T. Yucel, X. Wang, M.L. Lovett, D.L. Kaplan, Materials fabrication from Bombyx mori silk fibroin, Nature protocols, 6 (2011) 1612-1631.

[14] H. Yamada, H. Nakao, Y. Takasu, K. Tsubouchi, Preparation of undegraded native molecular fibroin solution from silkworm cocoons, Mat Sci Eng C-Bio S, 14 (2001) 41-46.

[15] L.S. Wray, X. Hu, J. Gallego, I. Georgakoudi, F.G. Omenetto, D. Schmidt, D.L. Kaplan, Effect of processing on silk-based biomaterials: reproducibility and biocompatibility, Journal of biomedical materials research. Part B, Applied biomaterials, 99 (2011) 89-101.

[16] A. Matsumoto, J. Chen, A.L. Collette, U.J. Kim, G.H. Altman, P. Cebe, D.L. Kaplan, Mechanisms of silk fibroin sol-gel transitions, J. Phys. Chem. B, 110 (2006) 21630-21638.

[17] U.J. Kim, J. Park, C. Li, H.J. Jin, R. Valluzzi, D.L. Kaplan, Structure and properties of silk hydrogels, Biomacromolecules, 5 (2004) 786-792.

[18] Zainuddin, T.T. Le, Y. Park, T.V. Chirila, P.J. Halley, A.K. Whittaker, The behavior of aged regenerated Bombyx mori silk fibroin solutions studied by (1)H NMR and rheology, Biomaterials, 29 (2008) 4268-4274.

[19] Q. Lu, H. Zhu, C. Zhang, F. Zhang, B. Zhang, D.L. Kaplan, Silk self-assembly mechanisms and control from thermodynamics to kinetics, Biomacromolecules, 13 (2012) 826-832.

[20] S. Bai, H. Han, X. Huang, W. Xu, D.L. Kaplan, H. Zhu, Q. Lu, Silk scaffolds with tunable mechanical capability for cell differentiation, Acta Biomater, 20 (2015) 22-31.

[21] D.L. Kaplan, J.A. KLUGE, F.G. Omenetto, Low molecular weight silk compositions and stabilizing silk compositions, in, Google Patents, 2015.

[22] D.-H. Kim, J. Viventi, J.J. Amsden, J. Xiao, L. Vigeland, Y.-S. Kim, J.A. Blanco, B. Panilaitis, E.S. Frechette, D. Contreras, Dissolvable films of silk fibroin for ultrathin conformal bio-integrated electronics, Nature materials, 9 (2010) 511-517. 
[23] H. Tao, B. Marelli, M. Yang, B. An, S. Onses, J.A. Rogers, D.L. Kaplan, F.G. Omenetto, Inkjet Printing of Regenerated Silk Fibroin: From Printable Forms to Printable Functions, Advanced Materials, (2015).

[24] X. Wang, X. Hu, A. Daley, O. Rabotyagova, P. Cebe, D.L. Kaplan, Nanolayer biomaterial coatings of silk fibroin for controlled release, J. Controlled Release, 121 (2007) 190-199.

[25] T. Asakura, A. Kuzuhara, R. Tabeta, H. Saito, Conformational characterization of Bombyx mori silk fibroin in the solid state by high-frequency carbon-13 cross polarization-magic angle spinning NMR, x-ray diffraction, and infrared spectroscopy, Macromolecules, 18 (1985) 18411845.

[26] S.J. He, R. Valluzzi, S.P. Gido, Silk I structure in Bombyx mori silk foams, Int J Biol Macromol, 24 (1999) 187-195.

[27] X. Tang, M.J. Pikal, Design of freeze-drying processes for pharmaceuticals: practical advice, Pharm Res, 21 (2004) 191-200.

[28] J.A. Kluge, B. Kahn, J. Brown, F.G. Omenetto, D.L. Kaplan, Optimizing molecular weight of lyophilized silk as a shelf-stable source material, ACS Biomaterials Science and Engineering, In review (2015).

[29] J.F. Carpenter, M.J. Pikal, B.S. Chang, T.W. Randolph, Rational design of stable lyophilized protein formulations: Some practical advice, Pharmaceut Res, 14 (1997) 969-975.

[30] Q. Lu, X. Wang, X. Hu, P. Cebe, F. Omenetto, D.L. Kaplan, Stabilization and release of enzymes from silk films, Macromol. Biosci., 10 (2010) 359-368.

[31] B.D. Lawrence, M. Cronin-Golomb, I. Georgakoudi, D.L. Kaplan, F.G. Omenetto, Bioactive silk protein biomaterial systems for optical devices, Biomacromolecules, 9 (2008) 1214-1220.

[32] K. Tsioris, W.K. Raja, E.M. Pritchard, B. Panilaitis, D.L. Kaplan, F.G. Omenetto, Fabrication of Silk Microneedles for Controlled-Release Drug Delivery, Advanced Functional Materials, 22 (2012) 330-335.

[33] J. Qian, Y. Liu, H. Liu, T. Yu, J. Deng, An amperometric new methylene blue N-mediating sensor for hydrogen peroxide based on regenerated silk fibroin as an immobilization matrix for peroxidase, Anal Biochem, 236 (1996) 208-214.

[34] M. Demura, T. Asakura, T. Kuroo, Immobilization of biocatalysts with Bombyx mori silk fibroin by several kinds of physical treatment and its application to glucose sensors, Biosensors, 4 (1989) 361-372.

[35] A. Kuzuhara, T. Asakura, R. Tomoda, T. Matsunaga, Use of silk fibroin for enzyme membrane, Journal of Biotechnology, 5 (1987) 199-207. 
[36] S. Lu, X. Wang, Q. Lu, X. Hu, N. Uppal, F.G. Omenetto, D.L. Kaplan, Stabilization of enzymes in silk films, Biomacromolecules, 10 (2009) 1032-1042.

[37] P.B. Dennis, A.Y. Walker, M.B. Dickerson, D.L. Kaplan, R.R. Naik, Stabilization of organophosphorus hydrolase by entrapment in silk fibroin: formation of a robust enzymatic material suitable for surface coatings, Biomacromolecules, 13 (2012) 2037-2045.

[38] J. Zhang, E. Pritchard, X. Hu, T. Valentin, B. Panilaitis, F.G. Omenetto, D.L. Kaplan, Stabilization of vaccines and antibiotics in silk and eliminating the cold chain, Proceedings of the National Academy of Sciences of the United States of America, 109 (2012) 11981-11986.

[39] T.D. Sutherland, A. Sriskantha, J.S. Church, T. Strive, H.E. Trueman, T. Kameda, Stabilization of viruses by encapsulation in silk proteins, ACS applied materials \& interfaces, 6 (2014) 18189-18196.

[40] Y.H. Wu, Q.C. Shen, S.S. Hu, Direct electrochemistry and electrocatalysis of heme-proteins in regenerated silk fibroin film, Anal Chim Acta, 558 (2006) 179-186.

[41] P. Domachuk, H. Perry, J.J. Amsden, D.L. Kaplan, F.G. Omenetto, Bioactive "self-sensing" optical systems, Applied physics letters, 95 (2009).

[42] J.G. Hardy, L.M. Romer, T.R. Scheibel, Polymeric materials based on silk proteins, Polymer, 49 (2008) 4309-4327.

[43] K. Schacht, T. Scheibel, Processing of recombinant spider silk proteins into tailor-made materials for biomaterials applications, Curr Opin Biotech, 29 (2014) 62-69.

[44] S. Gomes, I.B. Leonor, J.F. Mano, R.L. Reis, D.L. Kaplan, Spider silk-bone sialoprotein fusion proteins for bone tissue engineering, Soft Matter, 7 (2011) 4964-4973.

[45] J. Huang, C. Wong, A. George, D.L. Kaplan, The effect of genetically engineered spider silk-dentin matrix protein 1 chimeric protein on hydroxyapatite nucleation, Biomaterials, 28 (2007) 2358-2367.

[46] A. Lammel, M. Schwab, M. Hofer, G. Winter, T. Scheibel, Recombinant spider silk particles as drug delivery vehicles, Biomaterials, 32 (2011) 2233-2240.

[47] M. Hofer, G. Winter, J. Myschik, Recombinant spider silk particles for controlled delivery of protein drugs, Biomaterials, 33 (2012) 1554-1562.

[48] K. Numata, A.J. Mieszawska-Czajkowska, L.A. Kvenvold, D.L. Kaplan, Silk-Based Nanocomplexes with Tumor-Homing Peptides for Tumor-Specific Gene Delivery, Macromolecular bioscience, 12 (2012) 75-82.

[49] C. Blum, A. Nichtl, T. Scheibel, Spider Silk Capsules as Protective Reaction Containers for Enzymes, Advanced Functional Materials, 24 (2014) 763-768. 
[50] T.D. Sutherland, A. Sriskantha, J.S. Church, T. Strive, H.E. Trueman, T. Kameda, Stabilization of Viruses by Encapsulation in Silk Proteins, ACS applied materials \& interfaces, 6 (2014) 18189-18196.

[51] T.D. Rapson, J.S. Church, H.E. Trueman, H. Dacres, T.D. Sutherland, S.C. Trowell, Micromolar biosensing of nitric oxide using myoglobin immobilized in a synthetic silk film, Biosens Bioelectron, 62 (2014) 214-220.

[52] W.W. Huang, A. Rollett, D.L. Kaplan, Silk-elastin-like protein biomaterials for the controlled delivery of therapeutics, Expert opinion on drug delivery, 12 (2015) 779-791.

[53] D. Liu, D. Ren, H. Huang, J. Dankberg, R. Rosenfeld, M.J. Cocco, L. Li, D.N. Brems, R.L. Remmele, Jr., Structure and stability changes of human IgG1 $\mathrm{Fc}$ as a consequence of methionine oxidation, Biochemistry, 47 (2008) 5088-5100.

[54] Q. Luo, M.K. Joubert, R. Stevenson, R.R. Ketchem, L.O. Narhi, J. Wypych, Chemical Modifications in Therapeutic Protein Aggregates Generated under Different Stress Conditions, Journal of Biological Chemistry, 286 (2011) 25134-25144.

[55] F. Mulinacci, M.A.H. Capelle, R. Gurny, A.F. Drake, T. Arvinte, Stability of Human Growth Hormone: Influence of Methionine Oxidation on Thermal Folding, Journal of Pharmaceutical Sciences, 100 (2011) 451-463.

[56] A.A. Wakankar, R.T. Borchardt, C. Eigenbrot, S. Shia, Y.J. Wang, S.J. Shire, J.L. Liu, Aspartate isomerization in the complementarity-determining regions of two closely related monoclonal antibodies, Biochemistry, 46 (2007) 1534-1544.

[57] E.J. McNally, Protein Formulation and Delivery, Marcel Dekker, Inc, New York, 2000.

[58] A.L. Daughery, R.J. Mrsny, Formulation and delivery issues for monoclonal antibody therapeutics, Advanced drug delivery reviews, 58 (2006) 686-706.

[59] A. Hawe, M. Wiggenhorn, M. van de Weert, J.H.O. Garbe, H.-C. Mahler, W. Jiskoot, Forced degradation of therapeutic proteins, Journal of Pharmaceutical Sciences, 101 (2012) 895913.

[60] W. Jiskoot, T.W. Randolph, D.B. Volkin, C.R. Middaugh, C. Schoneich, G. Winter, W. Friess, D.J. Crommelin, J.F. Carpenter, Protein instability and immunogenicity: roadblocks to clinical application of injectable protein delivery systems for sustained release, J. Pharm. Sci., 101 (2012) 946-954.

[61] M.C. Manning, D.K. Chou, B.M. Murphy, R.W. Payne, D.S. Katayama, Stability of protein pharmaceuticals: an update, Pharm Res, 27 (2010) 544-575.

[62] H.C. Mahler, W. Friess, U. Grauschopf, S. Kiese, Protein Aggregation: Pathways, Induction Factors and Analysis, J. Pharm. Sci., 98 (2009) 2909-2934. 
[63] B.S. Chang, B. Yeung, Physical stability of protein pharmaceuticals, in: F. Jameel, S. Hershenson (Eds.) Formulation and process development strategies for manufacturing biopharmaceuticals, John Wiley \& Sons, Hoboken, New Jersey, 2010, pp. 69-104.

[64] H.-C. Mahler, W. Friess, U. Grauschopf, S. Kiese, Protein Aggregation: Pathways, Induction Factors and Analysis, Journal of Pharmaceutical Sciences, 98 (2009) 2909-2934.

[65] M.E.M. Cromwell, E. Hilario, F. Jacobson, Protein Aggregation and Bioprocessing, AAPS Journal, 8 (2006) 573-579.

[66] P.L. Privalov, Stability of proteins. Proteins which do not present a single cooperative system, Adv Protein Chem, 35 (1982) 1-104.

[67] R. Jaenicke, Stability and stabilization of globular proteins in solution, J Biotechnol, 79 (2000) 193-203.

[68] B. Perez-Ramirez, N. Guziewicz, B.R. Simler, Preformulation research: assessing protein solution behavior during early development, in: F. Jameel, S. Hershenson (Eds.) Formulation and process development strategies for manufacturing biopharmaceuticals, John Wiley \& Sons, Hoboken, New Jersey, 2010, pp. 119-146.

[69] V.K. Mulligan, A. Kerman, R.C. Laister, P.R. Sharda, P.E. Arslan, A. Chakrabartty, Early Steps in Oxidation-Induced SOD1 Misfolding: Implications for Non-Amyloid Protein Aggregation in Familial ALS, Journal of Molecular Biology, 421 (2012) 631-652.

[70] E.Y. Chi, S. Krishnan, T.W. Randolph, J.F. Carpenter, Physical stability of proteins in aqueous solution: Mechanism and driving forces in nonnative protein aggregation, Pharmaceut Res, 20 (2003) 1325-1336.

[71] S.N. Timasheff, Control of protein stability and reactions by weakly interacting cosolvents: The simplicity of the complicated, Advances in Protein Chemistry, Vol 51, 51 (1998) 355-432.

[72] S.N. Timasheff, The Control of Protein Stability and Association by Weak-Interactions with Water - How Do Solvents Affect These Processes, Annu Rev Bioph Biom, 22 (1993) 67-97.

[73] J.J. Valente, R.W. Payne, M.C. Manning, W.W. Wilson, C.S. Henry, Colloidal behavior of proteins: Effects of the second virial coefficient on solubility, crystallization and aggregation of proteins in aqueous solution, Curr Pharm Biotechno, 6 (2005) 427-436.

[74] D. Asthagiri, B.L. Neal, A.M. Lenhoff, Calculation of short-range interactions between proteins, Biophys Chem, 78 (1999) 219-231.

[75] J.R. Alford, B.S. Kendrick, J.F. Carpenter, T.W. Randolph, Measurement of the second osmotic virial coefficient for protein solutions exhibiting monomer-dimer equilibrium (vol 377, pg 128, 2008), Anal Biochem, 383 (2008) 349-349. 
[76] S. Yadav, T.M. Laue, D.S. Kalonia, S.N. Singh, S.J. Shire, The Influence of Charge Distribution on Self-Association and Viscosity Behavior of Monoclonal Antibody Solutions, Mol. Pharm., 9 (2012) 791-802.

[77] J. Jezek, M. Rides, B. Derham, J. Moore, E. Cerasoli, R. Simler, B. Perez-Ramirez, Viscosity of concentrated therapeutic protein compositions, Advanced Drug Delivery Reviews, 63 (2011) 1107-1117.

[78] S.V. Sule, J.K. Cheung, V. Antochshuk, A.S. Bhalla, C. Narasimhan, S. Baisdell, M. Shameem, P.M. Tessier, Solution pH That Minimizes Self-Association of Three Monoclonal Antibodies Is Strongly Dependent on Ionic Strength, Mol. Pharm., 9 (2012) 744-751.

[79] S. Yadav, S.J. Shire, D.S. Kalonia, Viscosity behavior of high-concentration monoclonal antibody solutions: Correlation with interaction parameter and electroviscous effects, J. Pharm. Sci., 101 (2012) 998-1011.

[80] H. Fan, J. Liu, W. Ren, Z. Zheng, Y. Zhang, X. Yang, H. Li, X. Wang, G. Zou, pH Induces Thermal Unfolding of UTI: An Implication of Reversible and Irreversible Mechanism Based on the Analysis of Thermal Stability, Thermodynamic, Conformational Characterization, J Fluoresc, 18 (2008) 305-317.

[81] K.J. Ellis, J.F. Morrison, Buffers of constant ionic strength for studying pH-dependent processes, Methods Enzymol, 87 (1982) 405-426.

[82] D.S. Katayama, R. Nayar, D.K. Chou, J.J. Valente, J. Cooper, C.S. Henry, D.G. Vander Velde, L. Villarete, C.P. Liu, M.C. Manning, Effect of buffer species on the thermally induced aggregation of interferon-tau, Journal of Pharmaceutical Sciences, 95 (2006) 1212-1226.

[83] D. Kameoka, E. Masuzaki, T. Ueda, T. Imoto, Effect of Buffer Species on the Unfolding and the Aggregation of Humanized IgG, J Biochem, 142 (2007) 383-391.

[84] J. Jezek, D.X. Chen, L. Watson, J. Crawford, S. Perkins, A. Tyagi, L. Jones-Braun, A heatstable hepatitis B vaccine formulation, Hum. Vaccines, 5 (2009) 529-535.

[85] J. Jezek, Increasing the protein stability of an aqueous composition comprising a protein by determining a $\mathrm{pH}$ at which the protein has stability, adding a displacement buffer, and adjusting the $\mathrm{pH}$ of the composition, in, ARECOR LTD (AREC-Non-standard) JEZEK J (JEZEIndividual), pp. 2114456-A2114452:

[86] T. Arakawa, S.N. Timasheff, Stabilization of protein structure by sugars, Biochemistry, 21 (1982) 6536-6544.

[87] J.C. Lee, S.N. Timasheff, The stabilization of proteins by sucrose, J Biol Chem, 256 (1981) 7193-7201. 
[88] R. Bhat, S.N. Timasheff, Steric exclusion is the principal source of the preferential hydration of proteins in the presence of polyethylene glycols, Protein Sci, 1 (1992) 1133-1143.

[89] K. Gekko, S.N. Timasheff, Mechanism of protein stabilization by glycerol: preferential hydration in glycerol-water mixtures, Biochemistry, 20 (1981) 4667-4676.

[90] B.M. Baynes, D.I.C. Wang, B.L. Trout, Role of Arginine in the Stabilization of Proteins against Aggregation, Biochemistry, 44 (2005) 4919-4925.

[91] T. Arakawa, D. Ejima, K. Tsumoto, N. Obeyama, Y. Tanaka, Y. Kita, S.N. Timasheff, Suppression of protein interactions by arginine: A proposed mechanism of the arginine effects, Biophys Chem, 127 (2007) 1-8.

[92] B. Kerwin, A, Polysorbates 20 and 80 used in the formulation of protein biotherapeutics: Structure and degradation pathways, in: Journal of Pharmaceutical Sciences, 2007, pp. 1-12.

[93] E.M. Topp, L. Zhang, H. Zhao, R.W. Payne, G.J. Evans, M.C. Manning, Chemical instability in peptide and protein pharmaceuticals, in: F. Jameel, S. Hershenson (Eds.) Formulation and process development strategies for manufacturing biopharmaceuticals, John Wiley \& Sons, Hoboken, New Jersey, 2010, pp. 41-67.

[94] H. Liu, G. Gaza-Bulseco, J. Sun, Characterization of the stability of a fully human monoclonal IgG after prolonged incubation at elevated temperature, Journal of Chromatography B, 837 (2006) 35-43.

[95] B. Peters, B.L. Trout, Asparagine Deamidation: pH-Dependent Mechanism from Density Functional Theory, Biochemistry, 45 (2006) 5384-5392.

[96] A.A. Wakankar, R.T. Borchardt, Formulation considerations for proteins susceptible to asparagine deamidation and aspartate isomerization, J. Pharm. Sci., 95 (2006) 2321-2336.

[97] K. Patel, R.T. Borchardt, Chemical Pathways of Peptide Degradation. II. Kinetics of Deamidation of an Asparaginyl Residue in a Model Hexapeptide, Pharm Res, 7 (1990) 703-711.

[98] W. Zhang, M.J. Czupryn, P.T. Boyle, J. Amari, Characterization of asparagine deamidation and aspartate isomerization in recombinant human interleukin-11, Pharmaceut Res, 19 (2002) 1223-1231.

[99] R.T.B. Aditya A. Wakankar, Formulation considerations for proteins susceptible to asparagine deamidation and aspartate isomerization, Journal of Pharmaceutical Sciences, 95 (2006) 2321-2336.

[100] A.S. Inglis, Cleavage at Aspartic-Acid, Method Enzymol, 91 (1983) 324-332.

[101] B.J. Marsden, T.M. Nguyen, P.W. Schiller, Spontaneous degradation via diketopiperazine formation of peptides containing a tetrahydroisoquinoline-3-carboxylic acid residue in the 2- 
position of the peptide sequence, International journal of peptide and protein research, 41 (1993) 313-316.

[102] L. Yu, A. Vizel, M.B. Huff, M. Young, R.L. Remmele, Jr., B. He, Investigation of Nterminal glutamate cyclization of recombinant monoclonal antibody in formulation development, Journal of pharmaceutical and biomedical analysis, 42 (2006) 455-463.

[103] E.R. Stadtman, Metal ion-catalyzed oxidation of proteins: biochemical mechanism and biological consequences, Free radical biology \& medicine, 9 (1990) 315-325.

[104] C. Schoneich, Mechanisms of metal-catalyzed oxidation of histidine to 2-oxo-histidine in peptides and proteins, Journal of pharmaceutical and biomedical analysis, 21 (2000) 1093-1097.

[105] E.R. Stadtman, Oxidation of Free Amino-Acids and Amin-Acid Residues in Proteins by Radiolysis and by Metal-Catalyzed Reactions, Annual Review of Biochemistry, 62 (1993) 797821.

[106] C.L. Hawkins, M.J. Davies, Generation and propagation of radical reactions on proteins, Bba-Bioenergetics, 1504 (2001) 196-219.

[107] H. Liu, G. Gaza-Bulseco, L. Zhou, Mass Spectrometry Analysis of Photo-Induced Methionine Oxidation of a Recombinant Human Monoclonal Antibody, Journal of the American Society for Mass Spectrometry, 20 (2009) 525-528.

[108] E.T. Duenas, R. Keck, A. De Vos, A.J.S. Jones, J.L. Cleland, Comparison between light induced and chemically induced oxidation of rhVEGF, Pharmaceut Res, 18 (2001) 1455-1460.

[109] S. Horvat, A. Jakas, Peptide and amino acid glycation: New insights into the Maillard reaction, J Pept Sci, 10 (2004) 119-137.

[110] S.A. Hill, W. MacNaughtan, I.A. Farhat, T.R. Noel, R. Parker, S.G. Ring, M.J. Whitcombe, The effect of thermal history on the Maillard reaction in a glassy matrix, J Agr Food Chem, 53 (2005) 10213-10218.

[111] T. Geiger, S. Clarke, Deamidation, isomerization, and racemization at asparaginyl and aspartyl residues in peptides. Succinimide-linked reactions that contribute to protein degradation, J. Biol. Chem., 262 (1987) 785-794.

[112] M.C. Manning, K. Patel, R.T. Borchardt, Stability of protein pharmaceuticals, Pharm Res, 6 (1989) 903-918.

[113] H.T. Wright, Nonenzymatic deamidation of asparaginyl and glutaminyl residues in proteins, Critical reviews in biochemistry and molecular biology, 26 (1991) 1-52.

[114] S.J. Wearne, T.E. Creighton, Effect of protein conformation on rate of deamidation: ribonuclease A, Proteins, 5 (1989) 8-12. 
[115] J. Fransson, E. Florin-Robertsson, K. Axelsson, C. Nyhlen, Oxidation of human insulinlike growth factor I in formulation studies: kinetics of methionine oxidation in aqueous solution and in solid state, Pharm Res, 13 (1996) 1252-1257.

[116] C.S.R.T.B. Shihong Li, Chemical instability of protein pharmaceuticals: Mechanisms of oxidation and strategies for stabilization, Biotechnology and Bioengineering, 48 (1995) 490-500.

[117] M.T. Fisher, E.R. Stadtman, Oxidative Modification of Escherichia-Coli GlutamineSynthetase - Decreases in the Thermodynamic Stability of Protein-Structure and Specific Changes in the Active-Site Conformation, Journal of Biological Chemistry, 267 (1992) 18721880 .

[118] A.A. Wakankar, R.T. Borchardt, Formulation considerations for proteins susceptible to asparagine deamidation and aspartate isomerization, Journal of Pharmaceutical Sciences, 95 (2006) 2321-2336.

[119] N.A. Guziewicz, A.J. Massetti, B.J. Perez-Ramirez, D.L. Kaplan, Mechanisms of monoclonal antibody stabilization and release from silk biomaterials, Biomaterials, 34 (2013) 7766-7775.

[120] E. Garber, S.J. Demarest, A broad range of $F_{a b}$ stabilities within a host of therapeutic IgGs, Biochemical and Biophysical Research Communications, 355 (2007) 751-757.

[121] K.A. Pikal-Cleland, N. Rodriguez-Hornedo, G.L. Amidon, J.F. Carpenter, Protein denaturation during freezing and thawing in phosphate buffer systems: Monomeric and tetrameric beta-galactosidase, Archives of Biochemistry and Biophysics, 384 (2000) 398-406.

[122] L.L. Chang, D. Shepherd, J. Sun, D. Ouellette, K.L. Grant, X.C. Tang, M.J. Pikal, Mechanism of protein stabilization by sugars during freeze-drying and storage: native structure preservation, specific interaction, and/or immobilization in a glassy matrix?, J. Pharm. Sci., 94 (2005) 1427-1444.

[123] M. Stefani, C.M. Dobson, Protein aggregation and aggregate toxicity: new insights into protein folding, misfolding diseases and biological evolution, J Mol Med-Jmm, 81 (2003) 678699.

[124] T. Geiger, S. Clarke, Deamidation, Isomerization, and Racemization at Asparaginyl and Aspartyl Residues in Peptides - Succinimide-Linked Reactions That Contribute to ProteinDegradation, Journal of Biological Chemistry, 262 (1987) 785-794.

[125] J.B. Rouget, T. Aksel, J. Roche, J.L. Saldana, A.E. Garcia, D. Barrick, C.A. Royer, Size and sequence and the volume change of protein folding, J Am Chem Soc, 133 (2011) 6020-6027.

[126] S. Shimizu, D.J. Smith, Preferential hydration and the exclusion of cosolvents from protein surfaces, Journal of Chemical Physics, 121 (2004) 1148-1154. 
[127] P.N. Atterberry, T.J. Roark, S.Y. Severt, M.L. Schiller, J.M. Antos, A.R. Murphy, Sustained Delivery of Chemokine CXCL12 from Chemically Modified Silk Hydrogels, Biomacromolecules, 16 (2015) 1582-1589.

[128] M.T. Cicerone, M.J. Pikal, K.K. Qian, Stabilization of proteins in solid form, Advanced drug delivery reviews, (2015).

[129] J.F. Carpenter, J.H. Crowe, Modes of Stabiliation of a Protein by Organic Solutes during Desiccation, Cryobiology, 25 (1988) 459-470.

[130] H.R. Costantino, K. Griebenow, P. Mishra, R. Langer, A.M. Klibanov, Fourier-transform infrared spectroscopic investigation of protein stability in the lyophilized form, Biochimica et Biophysica Acta (BBA)-Protein Structure and Molecular Enzymology, 1253 (1995) 69-74.

[131] A.R. Murphy, D.L. Kaplan, Biomedical applications of chemically-modified silk fibroin, Journal of materials chemistry, 19 (2009) 6443-6450.

[132] F. Franks, R. Hatley, S. Mathias, Materials science and the production of shelf-stable biologicals, Biopharm-the Technology \& Business of Biopharmaceuticals, 4 (1991) 38-\&.

[133] L. Chang, M.J. Pikal, Mechanisms of Protein Stabilization in the Solid State, Journal of Pharmaceutical Sciences, 98 (2009) 2886-2908.

[134] P.G. Debenedetti, F.H. Stillinger, Supercooled liquids and the glass transition, Nature, 410 (2001) 259-267.

[135] J.J. Hill, E.Y. Shalaev, G. Zografi, The Importance of Individual Protein Molecule Dynamics in Developing and Assessing Solid State Protein Preparations, Journal of Pharmaceutical Sciences, 103 (2014) 2605-2614.

[136] S. Yoshioka, Y. Aso, Correlations between molecular mobility and chemical stability during storage of amorphous pharmaceuticals, Journal of Pharmaceutical Sciences, 96 (2007) 960-981.

[137] M.L. Williams, R.F. Landel, J.D. Ferry, The Temperature Dependence of Relaxation Mechanisms in Amorphous Polymers and Other Glass-forming Liquids, Journal of the American Chemical Society, 77 (1955) 3701-3707.

[138] S.P. Duddu, P.R. DalMonte, Effect of glass transition temperature on the stability of lyophilized formulations containing a chimeric therapeutic monoclonal antibody, Pharmaceut Res, 14 (1997) 591-595.

[139] M.T. Cicerone, J.F. Douglas, beta-Relaxation governs protein stability in sugar-glass matrices, Soft Matter, 8 (2012) 2983-2991. 
[140] M.J. Pikal, D. Rigsbee, M.L. Roy, D. Galreath, K.J. Kovach, B. Wang, J.F. Carpenter, M.T. Cicerone, Solid State Chemistry of Proteins: II. The Correlation of Storage Stability of FreezeDried Human Growth Hormone (hGH) with Structure and Dynamics in the Glassy Solid, Journal of Pharmaceutical Sciences, 97 (2008) 5106-5121.

[141] B. Wang, M.T. Cicerone, Y. Aso, M.J. Pikal, The impact of thermal treatment on the stability of freeze-dried amorphous pharmaceuticals: II. Aggregation in an IgG1 fusion protein, J. Pharm. Sci., 99 (2010) 683-700.

[142] D. Devineni, C. Gonschorek, M.T. Cicerone, Y. Xu, J.F. Carpenter, T.W. Randolph, Storage stability of keratinocyte growth factor-2 in lyophilized formulations: Effects of formulation physical properties and protein fraction at the solid-air interface, European Journal of Pharmaceutics and Biopharmaceutics, 88 (2014) 332-341.

[143] M.T. Cicerone, Q. Zhong, M. Tyagi, Picosecond Dynamic Heterogeneity, Hopping, and Johari-Goldstein Relaxation in Glass-Forming Liquids, Physical review letters, 113 (2014) 117801.

[144] H. Yu, K. Samwer, Y. Wu, W. Wang, Correlation between $\beta$ relaxation and self-diffusion of the smallest constituting atoms in metallic glasses, Physical review letters, 109 (2012) 095508.

[145] R.A. Riggleman, J.F. Douglas, J.J. de Pablo, Antiplasticization and the elastic properties of glass-forming polymer liquids, Soft Matter, 6 (2010) 292-304.

[146] L. Yu, X. Hu, D. Kaplan, P. Cebe, Dielectric Relaxation Spectroscopy of Hydrated and Dehydrated Silk Fibroin Cast from Aqueous Solution, Biomacromolecules, 11 (2010) 2766-2775.

[147] F.P. Seib, D.L. Kaplan, Doxorubicin-loaded silk films: drug-silk interactions and in vivo performance in human orthotopic breast cancer, Biomaterials, 33 (2012) 8442-8450.

[148] X. Wang, T. Yucel, Q. Lu, X. Hu, D.L. Kaplan, Silk nanospheres and microspheres from silk/pva blend films for drug delivery, Biomaterials, 31 (2010) 1025-1035.

[149] S.-J. He, R. Valluzzi, S.P. Gido, Silk I structure in Bombyx mori silk foams, Int J Biol Macromol, 24 (1999) 187-195.

[150] D.H. Kim, Y.S. Kim, J. Amsden, B. Panilaitis, D.L. Kaplan, F.G. Omenetto, M.R. Zakin, J.A. Rogers, Silicon electronics on silk as a path to bioresorbable, implantable devices, Applied physics letters, 95 (2009) 133701.

[151] H.J. Jin, J. Park, V. Karageorgiou, U.J. Kim, R. Valluzzi, P. Cebe, D.L. Kaplan, Waterstable silk films with reduced $\beta$-sheet content, Adv. Funct. Mater., 15 (2005) 1241-1247.

[152] Q. Lu, X. Hu, X. Wang, J.A. Kluge, S. Lu, P. Cebe, D.L. Kaplan, Water-insoluble silk films with silk I structure, Acta Biomater, 6 (2010) 1380-1387. 
[153] R.D. Deegan, O. Bakajin, T.F. Dupont, G. Huber, S.R. Nagel, T.A. Witten, Capillary flow as the cause of ring stains from dried liquid drops, Nature, 389 (1997) 827-829.

[154] N. Guziewicz, A. Best, B. Perez-Ramirez, D.L. Kaplan, Lyophilized silk fibroin hydrogels for the sustained local delivery of therapeutic monoclonal antibodies, Biomaterials, 32 (2011) 2642-2650.

[155] B.S. Chang, C.S. Randall, Use of Subambient Thermal-Analysis to Optimize Protein Lyophilization, Cryobiology, 29 (1992) 632-656.

[156] W. Wang, Lyophilization and development of solid protein pharmaceuticals, Int J Pharm, 203 (2000) 1-60.

[157] C. Vepari, D.L. Kaplan, Silk as a biomaterial, Prog. Polym. Sci., 32 (2007) 991.

[158] E.M. Pritchard, X. Hu, V. Finley, C.K. Kuo, D.L. Kaplan, Effect of silk protein processing on drug delivery from silk films, Macromolecular bioscience, 13 (2013) 311-320.

[159] J. Rnjak-Kovacina, T.M. DesRochers, K.A. Burke, D.L. Kaplan, The Effect of Sterilization on Silk Fibroin Biomaterial Properties, Macromolecular bioscience, (2015).

[160] P. Wadbua, B. Promdonkoy, S. Maensiri, S. Siri, Different properties of electrospun fibrous scaffolds of separated heavy-chain and light-chain fibroins of Bombyx mori, Int J Biol Macromol, 46 (2010) 493-501.

[161] B. Marelli, C.E. Ghezzi, A. Alessandrino, J.E. Barralet, G. Freddi, S.N. Nazhat, Silk fibroin derived polypeptide-induced biomineralization of collagen, Biomaterials, 33 (2012) 102108.

[162] B.B. Mandal, A. Grinberg, E.S. Gil, B. Panilaitis, D.L. Kaplan, High-strength silk protein scaffolds for bone repair, Proceedings of the National Academy of Sciences of the United States of America, 109 (2012) 7699-7704.

[163] S. Sohn, H.H. Strey, S.P. Gido, Phase behavior and hydration of silk fibroin, Biomacromolecules, 5 (2004) 751-757.

[164] K. Numata, P. Cebe, D.L. Kaplan, Mechanism of enzymatic degradation of beta-sheet crystals., Biomaterials, 31 (2010) 2926-2933.

[165] T. Yucel, P. Cebe, D.L. Kaplan, Vortex-induced injectable silk fibroin hydrogels, Biophysical journal, 97 (2009) 2044-2050.

[166] X. Wang, J.A. Kluge, G.G. Leisk, D.L. Kaplan, Sonication-induced gelation of silk fibroin for cell encapsulation, Biomaterials, 29 (2008) 1054-1064. 
[167] Y. Gotoh, M. Tsukada, N. Minoura, Y. Imai, Synthesis of poly(ethylene glycol)-silk fibroin conjugates and surface interaction between L-929 cells and the conjugates, Biomaterials, 18 (1997) 267-271.

[168] V. Karageorgiou, L. Meinel, S. Hofmann, A. Malhotra, V. Volloch, D. Kaplan, Bone morphogenetic protein-2 decorated silk fibroin films induce osteogenic differentiation of human bone marrow stromal cells, J. Biomed. Mater. Res. A, 71 (2004) 528-537.

[169] C.P. Vepari, D.L. Kaplan, Covalently immobilized enzyme gradients within threedimensional porous scaffolds, Biotechnology and Bioengineering, 93 (2006) 1130-1137.

[170] K.Y. Cai, K.D. Yao, S.B. Lin, Z.M. Yang, X.Q. Li, H.Q. Xie, T.W. Qing, L.B. Gao, Poly(D,L-lactic acid) surfaces modified by silk fibroin: effects on the culture of osteoblast in vitro, Biomaterials, 23 (2002) 1153-1160.

[171] Y.-Q. Zhang, Y. Ma, Y.-Y. Xia, W.-D. Shen, J.-P. Mao, X.-M. Zha, K. Shirai, K. Kiguchi, Synthesis of silk fibroin-insulin bioconjugates and their characterization and activities in vivo, Journal of Biomedical Materials Research Part B-Applied Biomaterials, 79B (2006) 275-283.

[172] Y.Q. Zhang, W.L. Zhou, W.D. Shen, Y.H. Chen, X.M. Zha, K. Shirai, K. Kiguchi, Synthesis, characterization and immunogenicity of silk fibroin-L-asparaginase bioconjugates, Journal of Biotechnology, 120 (2005) 315-326.

[173] Y. Gotoh, M. Tsukada, N. Minoura, Chemical modification of arginyl residues in silk fibroin: 1. Reaction of 1,2-cyclohexanedione in borate buffer, Int J Biol Macromol, 14 (1992) 198-200.

[174] Y. Tamada, Sulfation of silk fibroin by chlorosulfonic acid and the anticoagulant activity, Biomaterials, 25 (2004) 377-383.

[175] A.R. Murphy, P. St John, D.L. Kaplan, Modification of silk fibroin using diazonium coupling chemistry and the effects on hMSC proliferation and differentiation, Biomaterials, 29 (2008) 2829-2838.

[176] H. Zhao, E. Heusler, G. Jones, L. Li, V. Werner, O. Germershaus, J. Ritzer, T. Luehmann, L. Meinel, Decoration of silk fibroin by click chemistry for biomedical application, Journal of structural biology, 186 (2014) 420-430.

[177] D.J. Hines, D.L. Kaplan, Mechanisms of controlled release from silk fibroin films, Biomacromolecules, 12 (2011) 804-812.

[178] E. Wenk, A.R. Murphy, D.L. Kaplan, L. Meinel, H.P. Merkle, L. Uebersax, The use of sulfonated silk fibroin derivatives to control binding, delivery and potency of FGF-2 in tissue regeneration, Biomaterials, 31 (2010) 1403-1413. 
[179] A.S. Lammel, X. Hu, S.-H. Park, D.L. Kaplan, T.R. Scheibel, Controlling silk fibroin particle features for drug delivery, Biomaterials, 31 (2010) 4583-4591.

[180] M. Sandor, D. Enscore, P. Weston, E. Mathiowitz, Effect of protein molecular weight on release from micron-sized PLGA microspheres, Journal of controlled release, 76 (2001) 297-311.

[181] O. Germershaus, V. Werner, M. Kutscher, L. Meinel, Deciphering the mechanism of protein interaction with silk fibroin for drug delivery systems, Biomaterials, 35 (2014) 34273434.

[182] F.P. Seib, G.T. Jones, J. Rnjak-Kovacina, Y. Lin, D.L. Kaplan, pH-Dependent Anticancer Drug Release from Silk Nanoparticles, Advanced healthcare materials, (2013).

[183] I. Pallotta, J.A. Kluge, J. Moreau, R. Calabrese, D.L. Kaplan, A. Balduini, Characteristics of platelet gels combined with silk, Biomaterials, 35 (2014) 3678-3687.

[184] J. Brown, C.L. Lu, J. Coburn, D.L. Kaplan, Impact of silk biomaterial structure on proteolysis, Acta biomaterialia, 11 (2015) 212-221. 